\title{
WATER PRESSURE IN INTRA- AND SUBGLACIAL CHANNELS*
}

\author{
By Hans Röthlisberger \\ (Versuchsanstalt für Wasserbau, Hydrologie und Glaziologie an der Eidgenössischen \\ Technischen Hochschule, Zürich, Switzerland)
}

Aвstract. Water flowing in tubular channels inside a glacier produces frictional heat, which causes melting of the ice walls. However the channels also have a tendency to close under the overburden pressure. Using the equilibrium equation that at every cross-section as much ice is melted as flows in, differential equations are given for steady flow in horizontal, inclined and vertical channels at variable depth and for variable discharge, ice properties and channel roughness. It is shown that the pressure decreases with increasing discharge, which proves that water must flow in main arteries. The same argument is used to show that certain glacier lakes above long flat valley glaciers must form in times of low discharge and empty when the discharge is high, i.e. when the water head in the subglacial drainage system drops below the lake level. Under the conditions of the model an ice mass of uniform thickness does not float, i.e. there is no water layer at the bottom, when the bed is inclined in the down-hill direction, but it can float on a horizontal bed if the exponent $n$ of the law for the ice creep is small. It is further shown that basal streams (bottom conduits) and lateral streams at the hydraulic grade line (gradient conduits) can coexist. Time-dependent flow, local topography, ice motion, and sediment load are not accounted for in the theory, although they may strongly influence the actual course of the water. Computations have been carried out for the Gornergletscher where the bed topography is known and where some data are available on subglacial water pressure.

RÉsumé. Pression de l'eau dans les conduites intra- el sous-glaciaires. La condition suivante est admise: le rétrécissement de la conduite sous-glaciaire dû à la pression de la glace est compensé par la fusion provoquée par la transformation en chaleur des pertes de charge. Des équations différentielles pour l'écoulement stationnaire dans des conduites horizontales, inclinées et verticales en fonction de la profondeur en dessous de la surface du glacier, du débit, des propriétés de la glace et de la rugosité des parois de la conduite sont indiquées. Ainsi, il s'est avéré que la pression décroît lorsque le débit augmente, ce qui prouverait que l'eau s'écoule dans des artères principales. Une argumentation analogue montre que certains lacs de barrage glaciaire situés au-dessus d'une langue de glacier étendue doivent se former lorsque le débit est faible et se vident lorsque le débit est élevé, c'est-à-dire lorsque la ligne de charge du système de drainage sous-glaciaire descend en dessous du niveau du lac. Selon les hypothèses du modèle, une masse de glace d'épaisseur uniforme ne flotte pas, c'està-dire, il n'y a pas de couche d'eau au fond lorsque le lit est incliné vers l'aval mais elle peut flotter sur un lit horizontal lorsque l'exposant $n$ dans l'équation de fluage de la glace est petit. On montre que l'écoulement sous-glaciaire au "thalweg" et l'écoulement latéral le long de la ligne de charge peuvent être stables tous deux l'un à côté de l'autre. La variabilité dans le temps du débit ainsi que la topographie locale, les propriétés de la glace et le transport solide ne font pas partie de la théorie, mais ont certainement une grande influence sur le site de l'écoulement. Des calculs ont été effectués pour le Gornergletscher où la topographie du lit est connue et où il existe des mesures de la pression d'eau sous-glaciaire.

Zusammenfassung. Wasserdruck in intra- und subglazialen Gerinnen. Das in röhrenformigen Gerinnen im Gletscherinnern fliessende Wasser erzeugt Reibungswärme, wodurch an den Wandungen Eis wegschmilzt. Die Gerinne haben andererseits die Tendenz, sich unter dem Überlagerungsdruck zu schliessen. Mittels der Gleichgewichtsbedingung, dass in jedem Querschnitt gleichviel Eis wegschmilzt wie zufliesst werden Differentialgleichungen hergeleitet, die den Wasserdruck in Funktion der Überlagerung, der Abflussmenge, der Zähigkeit des Eises und der Rauhigkeit des Gerinnes für den Fall horizontaler, vertikaler und beliebig geneigter Röhren im stationären Zustand zu berechnen erlauben. Es wird gezeigt, dass der Druck mit zunehmender Durchflussmenge abnimmt, was bedeutet, dass sich das Wasser in Hauptadern sammeln muss. Aus dem gleichen Grund werden sich gewisse Gletscherseen oberhalb langer flacher Talgletscher zur Zeit geringen Abflusses füllen, während die Entleerung bei starkem Abfluss einsetzt, wenn also der Druckspiegel des subglazialen Drainagesystems unter den Seespiegel fällt. Eine Eismasse konstanter Mächtigkeit kann bei den für die Modellrechnung getroffenen Voraussetzungen nicht zum schwimmen kommen, $\mathrm{d}$. $\mathrm{h}$. es ist keine durchgehende Wasserschicht an der Gletscherunterfläche vorhanden, wenn das Gletscherbett talwärts geneigt ist. Bei horizontalem Bett könnte sich aber eine solche Wasserschicht bei kleinem Exponenten $n$ des Fliessgesetzes des Eises einstellen. Die Rechnung zeigt weiter, dass sowohl zentrale Gerinne (an der Basis des Gletschers im Talweg) als auch laterale Gerinne (längs der Energielinie) nebeneinander bestehen können. Weder zeitliche Änderungen des Abflusses, noch topographische Effekte an der Gletschersohle, Eisbewegung oder Sedimentführung werden dabei in der Theorie berücksichtigt, obschon diese Faktoren zweifelsohne den wirklichen Verlauf der subglazialen Wasserläufe mitbestimmen. Für den Gornergletscher, von dem ausser dem Sohlenprofil vereinzelte Werte des subglazialen Wasserdruckes zur Verfügung standen, sind Berechnungen durchgeführt worden.

* Presented at the Symposium on the Hydrology of Glaciers, 7-13 September 1969, Cambridge, England. 


\section{INTRODUGTION}

The question of where and how water circulates within glaciers is of considerable interest from various points of view. Direct observations at depth are extremely scarce and will probably be so for some time to come, while morphological features give information only on certain aspects usually limited to shallow depth. The interpretation of hydrological data as another alternative is largely ambiguous. The following is an attempt to deduce some basic laws for water courses within the glacier by applying physical theory to a plausible model.

In a typical temperate valley glacier a main stream emerges at the lowest point of the terminus, and there is little doubt that it extends backwards for at least some distance under the glacier. From the fact that the water carries a fair amount of sediment, it can be further inferred that the stream is located at the glacier bed. Sometimes the water can be observed welling up where it leaves the glacier, but very often it does not touch the roof for at least the last few metres or tens of metres of the channel. Nevertheless it is likely that further in the whole cross-section carries water in this case as well. Only this latter condition of "flow in a closed conduit under pressure" is of interest here, and the water pressure as a function of distance from the portal will be computed (the portal will in this context be taken as the point where the flow in a closed conduit goes over into open channel flow).

When water is moving through a conduit in ice some melting will occur at the wall owing to the frictional heat produced in the running water. At the same time the conduit will tend to close by mechanical deformation if the ice pressure is larger than the pressure in the water. In the steady-state condition when the discharge does not change with time anywhere in the system the melting will everywhere be compensated by closure. The steady flow of water together with the equilibrium of closure and melt rate are the principles used for the computation of pressure. These principles are equally valid for channels at the glacier bed or within the ice, so that the conduits are often referred to as located at the bed in order to facilitate the description of the general situation. However, because the position at the ice boundary is a complication in the theoretical treatment, a tubular conduit completely surrounded by ice is assumed for simplicity.

\section{TheOREtical WATER PRESSURE IN HORIZONTAL CONDUITS SURROUNDED BY IGE}

In the basic approach the conduit is assumed to be horizontal and of circular crosssection with radius $r$. The water pressure at an arbitrary distance $x$ from the portal is $p$, while it is $p+\mathrm{d} p$ at $x+\mathrm{d} x$; the water flows in the negative sense of the $x$-axis. The overburden pressure of the glacier is $P$. The pressure difference $P-p$ (termed the effective overburden pressure in soil mechanics) is then causing the ice to flow radially towards the axis of the circular hole (Fig. ra).

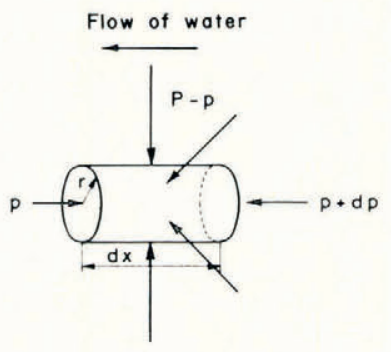

a. Horizontal conduit

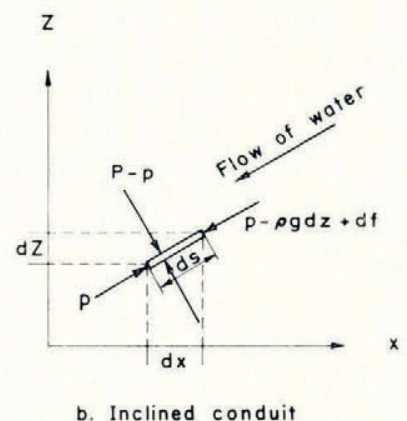

b. Inclined conduit

Fig. I. Horizontal and inclined conduit elements 
The volume of ice melt will be computed first. It depends on the frictional heat produced in the water, usually referred to as the energy loss in hydraulics. For convenience we assume instantaneous energy transfer from the water to the ice, so that the heat produced in a conduit element of length $\mathrm{d} x$ becomes available for melting within the same element. The water is then at the pressure melting point throughout. For a given discharge $Q$ and by neglecting velocity changes we can write for the energy loss per unit time in the conduit element:

$$
\mathrm{d} E=Q \mathrm{~d} p .
$$

Only part of the energy becomes available for melting, however, because the pressure change involves a temperature change as well, to bring the water to the pressure melting point. The energy $\mathrm{d} E$ from the pressure drop $\mathrm{d} p$ is reduced by the amount of energy $\mathrm{d} E_{\mathrm{t}}$ needed to adjust the water temperature to the reduced pressure, so that the energy available for melting becomes:

$$
\mathrm{d} E_{\mathrm{m}}=\mathrm{d} E-\mathrm{d} E_{\mathrm{t}} .
$$

With the change of pressure melting point with pressure $c_{\mathrm{t}}=-7.5 \times 1 \mathrm{IO}^{-3} \mathrm{deg} \mathrm{bar}^{-1}=$

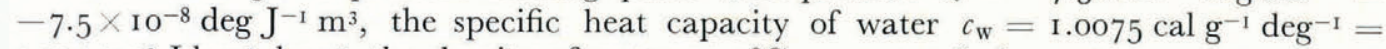
$4.22 \times \mathrm{IO}^{3} \mathrm{~J} \mathrm{~kg}^{-\mathrm{I}} \mathrm{deg}^{-1}$, the density of water at $\mathrm{O}^{\circ} \mathrm{C} \rho_{\mathrm{W}}=999.84 \mathrm{~kg} \mathrm{~m}^{-3}$,

$$
\mathrm{d} E_{\mathrm{t}}=-c_{\mathrm{t}} c_{\mathrm{w}} \rho_{\mathrm{w}} Q \mathrm{~d} p=0.3 \mathrm{I} 6 Q \mathrm{~d} p,
$$

hence

$$
\mathrm{d} E_{\mathrm{m}}=0.684 Q \mathrm{~d} p=0.684 \mathrm{~d} E .
$$

Roughly $\frac{2}{3}$ only of the frictional heat becomes available for melting. The volume $\mathrm{d} V_{\mathrm{m}}$ of ice melting per unit time in a channel section of length $\mathrm{d} x$ is then given by

$$
\mathrm{d} E_{\mathrm{m}}=c_{\mathrm{m}} \rho_{\mathrm{i}} \mathrm{d} V_{\mathrm{m}}
$$

where $c_{\mathrm{m}}$, the energy of fusion, $=79.7 \mathrm{I} \mathrm{cal} \mathrm{g}{ }^{-1}=3.34 \times 10^{5} \mathrm{~J} \mathrm{~kg}^{-1}$ and $\rho_{\mathrm{i}}$, the density of ice, $=917 \mathrm{~kg} \mathrm{~m}^{-3}$.

The creep of ice expressed as a volume $\mathrm{d} V_{\mathrm{c}}$ per unit time in the channel element of length $\mathrm{d} x$ is derived from the closure rate given by Nye (1953), which is

$$
\frac{\dot{r}}{r}=\left(\frac{P-p}{n A}\right)^{n} \text {. }
$$

This expression is based on the commonly used power law for the relation between strainrate and stress, in which $n$ and $A$ are the ice flow parameters to be discussed in more detail below. From simple geometrical considerations it follows that

$$
\mathrm{d} V_{\mathrm{c}}=2 r \pi \dot{r} \mathrm{~d} x=2 r^{2} \pi\left(\frac{P-p}{n A}\right)^{n} \mathrm{~d} x .
$$

Using now the equilibrium condition $\mathrm{d} V_{\mathrm{m}}=\mathrm{d} V_{\mathrm{e}}$, the differential equation

$$
\frac{\mathrm{d} p}{\mathrm{~d} x}=\frac{2 \pi c_{\mathrm{m}} \rho_{\mathrm{i}}}{0.684 Q}\left(\frac{P-p}{n A}\right)^{n} r^{2}
$$

is obtained. The conduit radius $r$ in this expression is still unknown, but it is related to $Q$ and $\mathrm{d} p / \mathrm{d} x$ and can be expressed in terms of these two quantities using appropriate hydraulic theory. According to the Gauckler-Manning-Strickler formula (Williams, 1970) the mean velocity for turbulent flow is given by

$$
\bar{v}=\frac{Q}{r^{2} \pi}=k R^{2 / 3}\left(\frac{\mathrm{I}}{\rho_{\mathrm{W}} g} \cdot \frac{\mathrm{d} p}{\mathrm{~d} x}\right)^{\mathrm{I} / 2}
$$


where $k$ is the roughness coefficient, $R$ the hydraulic radius $=r / 2$, and $g$ the acceleration due to gravity, thus

$$
r^{2}=\left(\frac{2^{4 / 3} \rho_{\mathrm{w}} g}{\pi^{2}}\right)^{3 / 8} k^{-3 / 4} Q^{3 / 4}\left(\frac{\mathrm{d} p}{\mathrm{~d} x}\right)^{-3 / 8} .
$$

Inserting Equation (10) in Equation (8) and solving for $\mathrm{d} p / \mathrm{d} x$ gives

$$
\frac{\mathrm{d} p}{\mathrm{~d} x}=B k^{-6 / 11}(n A)^{-8 n / \mathrm{II}} Q^{-2 / 11}(P-p)^{8 n / \mathrm{II}},
$$

with

$$
B=2^{12 / 11} \pi^{2 / 11}\left(\frac{c_{\mathrm{m}} \rho_{\mathrm{i}}}{0.684}\right)^{8 / \mathrm{II}}\left(\rho_{\mathrm{w}} \mathrm{g}\right)^{3 / 11}=6.33 \times 10^{7} \mathrm{~N} \mathrm{~m}^{-2} \mathrm{~m}^{-3 / 11} .
$$

This differential equation already permits us to draw some basic conclusions. It shows that the pressure gradient $\mathrm{d} p / \mathrm{d} x$ increases, as one would expect, with the pressure difference $(P-p)$, with ease of ice flow (small $A$ means low "viscosity"), and with channel roughness ( $k$ is small when the channel is rough; $n^{\prime}=\mathrm{I} / k$ is Manning's roughness coefficient). The dependence on $Q$ is fundamentally important. It is such that the greater the discharge the lesser the pressure gradient, and therefore, after integration over the distance $x$, the lesser the water pressure at a given distance from the snout. If two channels side by side should compete with each other, the larger one of the two would show the lower head of water and consequently drain the water away from the smaller one. This is taken as proof that intra- and subglacial water flows in discrete conduits with a tendency to form main arteries. * It should be noticed, however, that the dependence on $Q$ is very weak indeed; the roughness factor $k$ is by three orders more important than $Q$, and the factors $A$ and $(P-p)$ are more powerful by as much as 12 orders!

Explicit solutions of the differential Equation (I I) can easily be written down for simple cases, the boundary condition to be observed simply being that $p=0$ when $x=0$. The simplest case, consisting of constant discharge in a horizontal conduit under uniform thickness of ice, will be discussed in some detail; $k, n$ and $A$ are assumed to be constant, as is generally done in this paper, and $Q$ and $P$ are now also constant by definition. Assuming $n=3$, the solution of Equation (II) is

$$
x=\frac{\mathrm{II}}{{ }_{1} 3^{B}} k^{6 / \mathrm{II}}\left(3^{A}\right)^{24 / 11} Q^{2 / 1 \mathrm{I}}\left[(P-p)^{-\mathrm{I3} / \mathrm{II}}-P^{-13 / \mathrm{II}}\right] .
$$

The function $p(x)$ is a hyperbola with the line $p=P$ as the asymptote parallel to the abscissa. A set of such hyperbolas is given in Figure 2 for different values of roughness, ice flow coefficient or discharge. The ordinate on the left gives $(P-p)$ in pressure units. For a particular value $P_{\mathrm{I}}$ the origin of the abscissa is taken on a chosen curve so that $x=0$ for $p=0$, as indicated by the arrows in the figure; $p$ can then be read off the curve as a function of $x$. The same curve can thereby be used for arbitrary values of ice thickness, i.e. overburden pressure $P$. The curves are drawn in such a way that they go through a common point, which is the origin of the coordinates when the ice thickness is $250 \mathrm{~m}$, a value arbitrarily chosen to represent a medium-size glacier. In this case the fixed abscissa is given as well as a different ordinate which is calibrated in metres of head of water: $h=p / \rho_{\mathrm{w}} g$. The pressurehead curves are also referred to as hydraulic grade lines or piezometer lines (Fig. 4, definition on p. 184). Towards the right, the hyperbolas approach the "water-equivalent line" asymptotically. This is the height to which a column of water would rise to balance the

* A similar dependence of the pressure gradient on $Q$ is found for laminar flow, though with different exponents (Equation $(42)$ ). The present theory deals primarily with the condition in pre-existing large passages, where the flow is turbulent. 


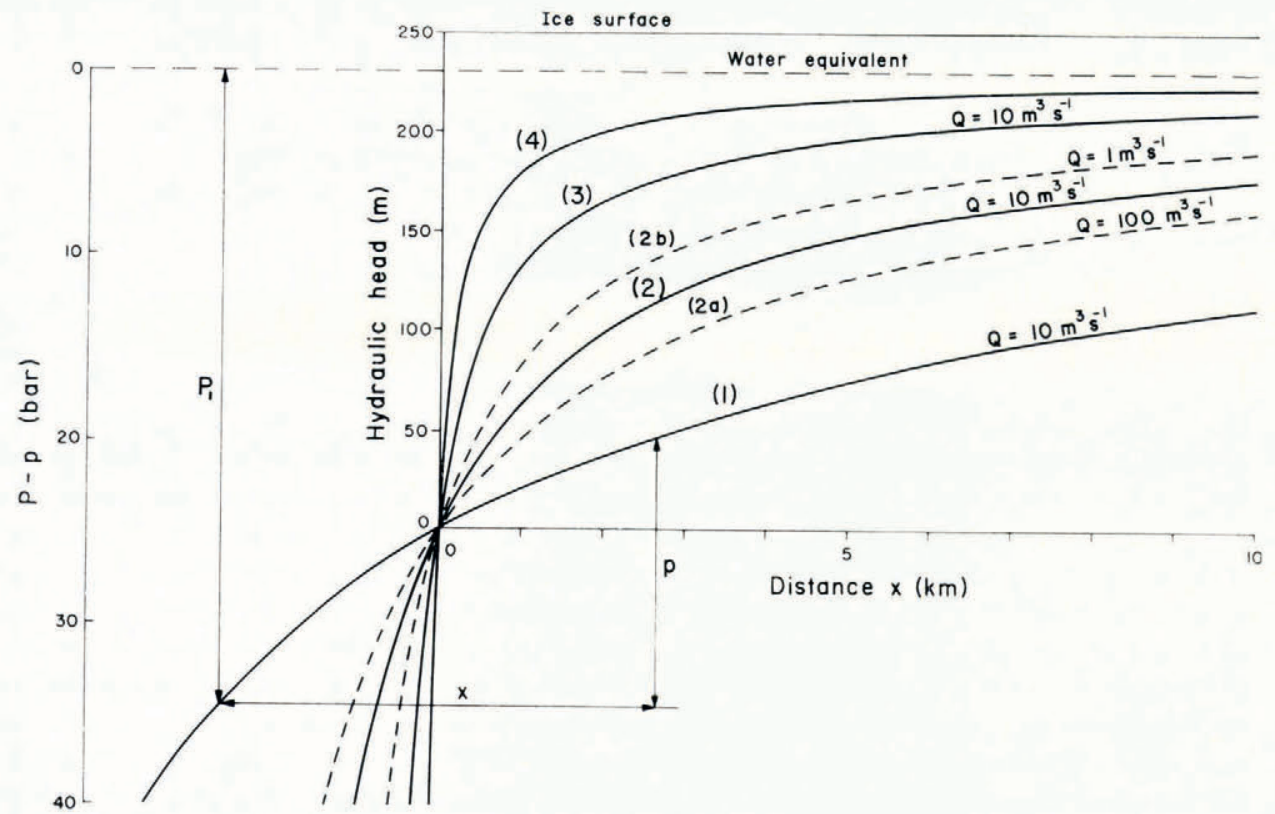

Fig. 2. Hydraulic grade lines for constant discharge in horizontal conduits at constant depth; ice surface and distance refer to a channel at the depth of $250 \mathrm{~m}$. The curves are numbered in accordance with Table $I$.

hydrostatic pressure of the ice at the channel elevation. The height of the ice surface is given by $H=P / \rho_{\mathrm{i}} g$. All curves rise fairly steeply at ice thicknesses larger than the $250 \mathrm{~m}$ chosen in the figure, so that in an extended ice sheet with a flat bottom the head of water can be expected to be at a lesser depth than $250 \mathrm{~m}$ at relatively small distances from the portal, even when the ice is much thicker, and also regardless of the curve parameters.

The selection of appropriate constants specifying the conduit characteristics and ice-flow properties is a major difficulty in numerical work. One way is to apply figures from textbooks and literature, the other is to try to fit observational data of water pressure directly. These two approaches have led to the values of $k$ and $A$ contained in Table I, which were used to compute the curves of Figure 2 according to the index numbers (I) to (4). A wide range of values for $k$ has been introduced, since it is a mere guess whether the conduit at depth is closer to a very smooth straight tubular opening in ice or a meandering boulderstrewn torrent at the bed. This question, however, has been found to be of lesser significance, the determining factor being the ice flow parameter $A$. In case ( $I$ ) the flow constant given

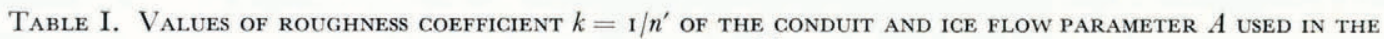
COMPUTATIONS FOR FIGURE 2

\begin{tabular}{|c|c|c|c|c|c|c|c|}
\hline $\begin{array}{l}\text { Curve } \\
\text { No. }\end{array}$ & $\begin{array}{c}k \\
\mathrm{~m}^{\mathrm{I} / 3} \mathrm{~s}^{-\mathrm{I}}\end{array}$ & $\begin{array}{c}n^{\prime} \\
\mathrm{m}^{-1 / 3} \mathrm{~s}\end{array}$ & $\begin{array}{c}\text { Conduit } \\
\text { comparable to }\end{array}$ & bar $s^{1 / 3}$ & bar $a^{1 / 3}$ & $\begin{array}{l}\text { Value for } A \\
\text { deduced from }\end{array}$ & Reference \\
\hline (I) & 50 & 0.02 & $\begin{array}{l}\text { rock tunnel of } \\
\text { medium } \\
\text { roughness }\end{array}$ & 727 & $2 \cdot 3$ & glacier flow & $\begin{array}{l}\text { Lliboutry ( } 1964 \text {, Tom I, } \\
\text { p. } 87 \text { ) }\end{array}$ \\
\hline (2) & $\begin{array}{r}10 \\
\text { (112 }\end{array}$ & $\begin{array}{l}\text { O.I } \\
\text { o.0o89 }\end{array}$ & $\begin{array}{l}\text { torrent } \\
\text { smooth pipe }\end{array}$ & $\begin{array}{l}5^{80} \\
317\end{array}$ & $\begin{array}{l}\text { I. } 84 \\
\text { г.00) }\end{array}$ & ice tunnel closure & Nye (1953, fig. I) \\
\hline (3) & Io & o.I & torrent & 317 & 1.00 & water pressure & See text \\
\hline (4) & 10 & 0.1 & torrent & I94 & $0.6 \mathrm{I}$ & $\begin{array}{l}\text { tunnel closure in } \\
\text { pressure zone }\end{array}$ & Nye (I953, fig. I) \\
\hline
\end{tabular}


by Lliboutry (1964, Tom I, p. 87) for temperate ice has been used. In case (2) Nye's (1953) analysis of the closure of the Vesl-Skautbre and Z'Mutt tunnels has served, with the figure of $A=580$ bar s $^{1 / 3}$ taken from Nye's graph for $n=3$ (it should be noticed that this figure is different from 489 bar $\mathrm{s}^{1 / 3.07}$ given in his paper). The same curve is obtained for a relatively smooth tube combined with the more mobile ice of case (3). Although for our application it seemed particularly appropriate to use ice-tunnel closure rates, it was found that an even lower value of $A$ was necessary in the analysis of the observed water pressure at the Gornergletscher to obtain agreement between observation and theory (case (3)). Finally in case (4) the value of $A$ fits the closure rate of the Arolla tunnel also shown on Nye's graph, assuming again $n=3$. (This last case is not realistic, since the strong deviation of $A$ seems to be related to local compressive stress in the glacier, and therefore the assumption of $n=3$ is not justified according to Glen (1958).)

A very large margin of possible pressure heads is included between the extreme cases (I) and (4). The factor $k^{6 / 11} A^{24 / 11}$ in Equation (12) changes by a factor of 43, 2.4 times from the variation of $k$ and 18 times from a change in $A$. The relative importance of $A$ has already been noted in relation to Equation (II), but naturally the final effect of each parameter depends on the total margin by which it may vary, not only on the exponent in the equations. If very smooth conduits were introduced in the discussion, $k$ would have a somewhat greater relative importance. However, the basic conclusion that one of the major difficulties of practical computations arises from the uncertainty of the ice flow properties is not altered.

In comparison with $k$ and $A$, the dependence of $p$ on the discharge $Q$ is relatively weak, but in practice the range over which $Q$ may vary is tremendous, and so its effect is not negligible. This is also illustrated in Figure 2. While all the solid lines are based on the same discharge of $Q=10 \mathrm{~m}^{3} \mathrm{~s}^{-1}$, curves $(2 \mathrm{a})$ and $(2 \mathrm{~b})$ have been obtained for $Q=100 \mathrm{~m}^{3} \mathrm{~s}^{-1}$ and $\mathrm{I} \mathrm{m}^{3} \mathrm{~s}^{-1}$, respectively, for the values of $k$ and $A$ in case (2).

The solution of Equation ( I I) for constant $Q$ and $P$ may now be written in a more general form so that $n$ may be varied:

$$
a C x=\left(\mathrm{I}-\frac{p}{P}\right)^{-a}-\mathrm{I} \quad \text { if } n \neq \mathrm{I} \mathrm{I} / 8
$$

whereas

$$
C x=-\ln \left(\mathrm{I}-\frac{p}{P}\right) \quad \text { if } n=\mathrm{I} \mathrm{I} / 8,
$$

with $a=8 n / \mathrm{I} \mathrm{I}-\mathrm{I}$ and $C=B k^{-6 / 11}(n A)^{-8 n / 11} Q^{-2 / 11} P^{a}$.

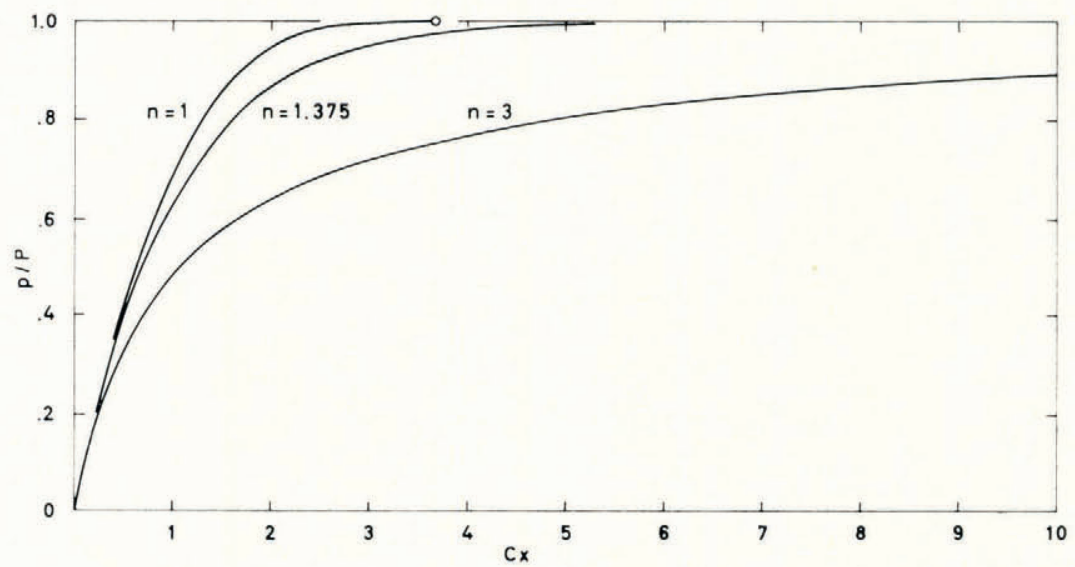

Fig. 3. Hydraulic grade lines for constant discharge in horizontal conduits at constant depth for different values of $n$. 
This equation is illustrated in Figure 3 , where the relative water pressure $p / P$ as a function of $C x$, the normalized distance, is shown for a few values of $n$. There is a remarkable difference between the curves with $n \geqslant$ I I $/ 8$, which approach the ultimate water pressure $P$ at infinite distance, and those with $n<\mathrm{I}$ I $/ 8$ where $p$ becomes equal to $P$ at a finite critical distance. Beyond the critical distance the water would spread out into a sheet; the ice slab would be afloat. Although $n=3$ is commonly used in ice mechanics there is experimental evidence (Butkovich and Landauer, 1960) that $n$ is smaller at small stresses, i.e. when $p$ approaches $P$, or also in zones of high strain-rate, as near the bed.

\section{INCLINED GIRGULAR CONDUITS}

With the above theory an arbitrarily shaped, two-dimensional glacier surface may be approximated, but it is not possible to apply it to an arbitrary glacier bed, because pressure changes are now not only related to the lost energy, but also to elevation changes. Both surface slope and channel slope will be taken into account in the next step. The channel will again be assumed to be located at the glacier bed for ease of explanation (and because actual water courses are likely to take this position), while the complications of the boundary will be neglected as before, treating the conduit as if it were surrounded by ice. The model used is thereby primarily one of an arbitrary channel within the glacier; the additional effects when it is actually located at the bottom will have to be discussed later.

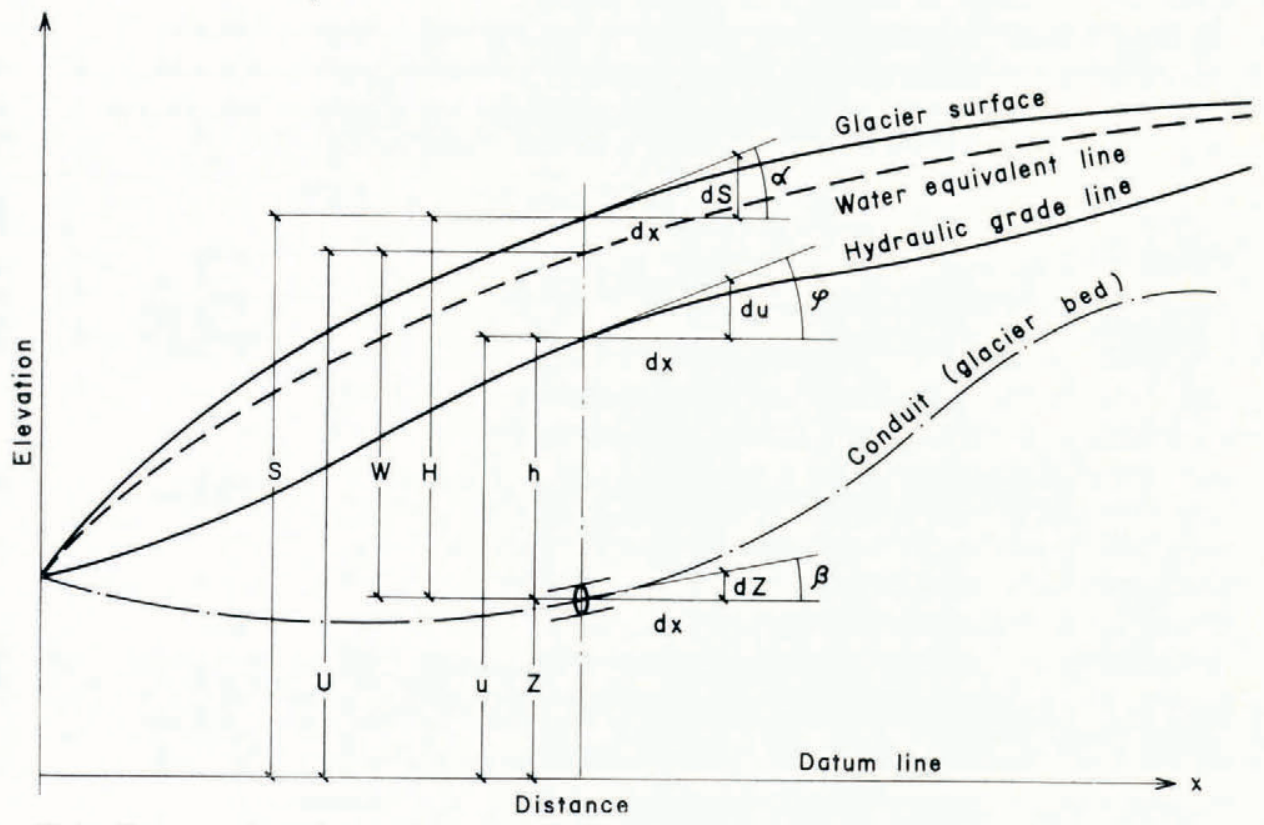

Fig. 4. Hydraulic terms and notations:

$h=$ pressure head $=$ piezometric or manometer height above the conduit.

$u=h+Z=$ height of the hydraulic grade line above the datum line $=$ pressure head + position head $=$ hydraulic head (above the datum line).

$H=$ ice thickness.

$S=H+Z=$ elevation of the glacier surface above the datum line.

$U=W+Z=$ elevation of the water-equivalent line above the datum line.

$W=$ water equivalent of ice thickness.

$Z=$ bed elevation above the datum line $=$ elevation head $=$ position head .

$\tan \alpha=$ surface slope.

$\tan \beta=\mathrm{d} Z / \mathrm{d} x=$ channel slope $=$ bed slope $=$ grade of conduit .

$\tan \varphi=\mathrm{d} u / \mathrm{d} x=(\mathrm{d} h+\mathrm{d} Z) / \mathrm{d} x=$ hydraulic gradient = ratio of the loss in the sum of the pressure head and position head to the flow distance.

$\mathrm{d} h / \mathrm{d} x=$ rate of change of pressure head. 
Some typical hydraulic expressions will be used. For detailed definitions see Betts and others (1962), but a few explanations will be given on the specific use of terms and notations in this paper. Figure 4 serves as an illustration. The glacier surface and the conduit at the glacier bed are shown as well as the water-equivalent line. This is the surface obtained if the ice is replaced by an equal mass of water, column by column, resting on the bed. The hydraulic grade line (or simply hydraulic grade) is defined as the line joining the elevations to which water would rise in pipes freely vented and under atmospheric pressure, also referred to as a hydraulic profile of the piezometric level of water at all points along the line, or simply piezometer line (Haefeli, I970). The term pressure head shall be assigned to the piezometric height $h$ of the hydraulic grade line above the conduit, while hydraulic head is used in reference to a horizontal datum line (reference horizon). The hydraulic head $u$ above the datum line is better suited to the presentation of results, while the pressure head $h$ is more directly applicable in the equations. There is a dual meaning connected with the term "head" in hydraulics, namely height and energy (pressure). In the latter case the energy is expressed as the vertical height through which a unit weight would have to fall to release the equivalent of energy. The kinetic energy may therefore also be expressed by a height, which is called the velocity head. The total head in a hydraulic system is the sum of pressure head and velocity head, and the line connecting points of total head is the energy line. Because the kinetic energy is neglected in this paper, the energy line is identical to the hydraulic line. However, pressure is not expressed generally as head of water here, but in SI- and related units $\left(\mathrm{N} \mathrm{m}^{-2}\right.$ and bar), and the terms used are: water pressure $p=\rho_{\mathrm{w}} g h$, overburden pressure $P=\rho_{\mathrm{i}} g H=\rho_{\mathrm{w}} g W$, pressure gradient $\mathrm{d} p / \mathrm{d} x=\rho_{\mathrm{w}} g \mathrm{~d} h / \mathrm{d} x ;$ further,

$$
\begin{gathered}
f=\rho_{\mathrm{w}} g u=\rho_{\mathrm{w}} g(h+Z)=p+\rho_{\mathrm{w}} g Z, \\
\frac{\mathrm{d} f}{\mathrm{~d} x}=\rho_{\mathrm{w}} g \frac{\mathrm{d} u}{\mathrm{~d} x}=\frac{\mathrm{d} p}{\mathrm{~d} x}+\rho_{\mathrm{w}} g \frac{\mathrm{d} Z}{\mathrm{~d} x}, \\
F=\rho_{\mathrm{w}} g U=\rho_{\mathrm{w}} g(W+Z)=P+\rho_{\mathrm{w}} g Z,
\end{gathered}
$$

where $f$ is the water pressure relative to the datum line, $\mathrm{d} f / \mathrm{d} x$ is the pressure gradient along the datum line and is, in other words, the gradient of pressure loss due to friction, and $F$ is the pressure of a column of water at the datum line extending upwards to the waterequivalent line.

The horizontal conduit element on which the computation for the horizontal channel has been based is replaced by an inclined element forming the angle $\beta$ with the horizontal (Fig. Ib), so that $\tan \beta=\mathrm{d} z / \mathrm{d} x$. The length of the conduit element is now $\mathrm{d} s=\mathrm{d} x / \cos \beta$. The $x$-axis is horizontal and points in the opposite direction to the flow of the water. The pressure at $x$ is $p$ and at $x+\mathrm{d} x$ it is $p+\mathrm{d} p$, whence

$$
\mathrm{d} p=\mathrm{d} f-\rho_{\mathrm{w}} g \mathrm{~d} Z=\mathrm{d} f-\rho_{\mathrm{w}} g \tan \beta \mathrm{d} x .
$$

This relation can also be inferred directly from Figure I, because when going from $x+\mathrm{d} x$ to $x$ the pressure change $-\mathrm{d} p$ must be the sum of a gain of pressure $\rho_{\mathrm{w}} g \mathrm{~d} Z$ by gravity and a loss of pressure $\mathrm{d} f$ caused by friction. The energy produced per unit time in the conduit element by friction is in analogy to Equation ( $\mathrm{I}$ ),

$$
\mathrm{d} E=Q \mathrm{~d} f,
$$

while the energy $\mathrm{d} E_{\mathrm{t}}$ needed to adjust the water temperature to the pressure melting point is given by Equation (3). The energy available for melting is then

$$
\mathrm{d} E_{\mathrm{m}}=Q \mathrm{~d} f-0.3 \mathrm{I} 6 Q \mathrm{~d} p,
$$

and the volume $\mathrm{d} V_{\mathrm{m}}$ of ice melting per unit time in the channel element is found from Equation (5): 


$$
\mathrm{d} V_{\mathrm{m}}=\frac{Q}{c_{\mathrm{m}} \rho_{\mathrm{i}}}(\mathrm{d} f-0.3 \mathrm{I} 6 \mathrm{~d} p) .
$$

Replacing $\mathrm{d} x$ by $\mathrm{d} s$ in Equation (7) and $\mathrm{d} p / \mathrm{d} x$ by $\mathrm{d} f / \mathrm{d} s$ in Equation (10) and using $\mathrm{d} V_{\mathrm{m}}=\mathrm{d} V_{\mathrm{c}}$ leads to

$$
\frac{Q}{c_{\mathrm{m}} \rho_{\mathrm{i}}}(\mathrm{d} f-0.3 \mathrm{I} 6 \mathrm{~d} p)=2 \pi\left(\frac{P-p}{n A}\right)^{n}\left(\frac{2^{4 / 3} \rho_{\mathrm{w}} g}{\pi^{2}}\right)^{3 / 8} k^{-3 / 4} Q^{3 / 4}\left(\frac{\mathrm{d} f}{\mathrm{~d} s}\right)^{-3 / 8} \mathrm{~d} s,
$$

and with Equation (14) and using $\mathrm{d} s=\mathrm{d} x / \cos \beta$,

with

$$
\begin{aligned}
\left(\frac{\mathrm{d} p}{\mathrm{~d} x}+\rho_{\mathrm{w}} g \tan \beta\right)^{1 \mathrm{II} / 8}-0.3 \mathrm{I} 6\left(\frac{\mathrm{d} p}{\mathrm{~d} x}+\rho_{\mathrm{W}} g \tan \beta\right)^{3 / 8} \frac{\mathrm{d} p}{\mathrm{~d} x} & \\
= & D k^{-3 / 4}(n A)^{-n} Q^{-1 / 4}(\cos \beta)^{-1 \mathrm{I} / 8}(P-p)^{n},
\end{aligned}
$$

$$
D=2^{3 / 2} \pi^{1 / 4} c_{\mathrm{m}} \rho_{\mathrm{i}}\left(\rho_{\mathrm{w}} g\right)^{3 / 8}=0.684 B^{11 / 8}=3.63 \times{ }^{10^{10}}\left(\mathrm{~N} \mathrm{~m}^{-2}\right)^{11 / 8} \mathrm{~m}^{-3 / 8} .
$$

Expressed in terms of $\mathrm{d} f / \mathrm{d} x$ and $f$ this equation becomes

$$
\left(\frac{\mathrm{d} f}{\mathrm{~d} x}\right)^{\mathrm{11} / 8}+0.462 \rho_{\mathrm{w}} g \tan \beta\left(\frac{\mathrm{d} f}{\mathrm{~d} x}\right)^{3 / 8}=\frac{D}{0.684} k^{-3 / 4}(n A)^{-n} Q^{-1 / 4}(\cos \beta)^{-11 / 8}(F-f)^{n},
$$

where $F-f=P-p$ from Equation (14). Evidently for horizontal conduits, where $\beta=0$ and $Z=0$, both equations reduce to Equation (I I).

Equation (20) has served to obtain $p$ as a function of $x$ by numerical integration, observing the boundary condition that $p=0$ for $x=0$ as before, or some other fixed relation at a given value of $x . P, Q$ and $\tan \beta$ have been inserted as known functions of $x$ (linear functions in polygonal fashion have been used), while $k, n$ and $A$ have been assumed to be constant. The Runge-Kutta integration method has been applied.

The results of numerical evaluation of a few simple model cases are presented in Figure 5 for the same constant discharge $Q=10 \mathrm{~m}^{3} \mathrm{~s}^{-1}$ as had been used for the solid lines in Figure 2. The index numbers (2) and (3) again refer to the channel roughness and ice flow parameters of Table I, and $n=3$ has been assumed as before. The upper and lower ice boundaries are given with solid lines. The ice bodies in (a) to (c) are simple wedges showing a linear increase of ice thickness from left to right. The water is flowing in a conduit at the bottom from right to left, horizontally in (a), descending in (b), and ascending in (c); case (d) is an inclined sheet of uniform thickness, (e) an ice body with horizontal surface on a base sloping downward in the flow direction, while in $(f)$ the water-equivalent line is horizontal and the base is ascending. The light dashed lines in the Figure represent the water equivalent of the ice bodies, and the heavy dashed ones give the hydraulic grade lines, which are the result of the computation.

There are cases where the hydraulic grade line remains between the base and the water equivalent line, but this is not generally true. In some instances it drops below the bed, which means that $p$ becomes negative (Fig. 5 b, e). This is the condition for suction, which may exist if no air can enter the conduit. It is, however, limited to atmospheric pressure less vapour pressure. If the suction reaches the full theoretical value, it accelerates the closure to the point when the conduit remains in equilibrium. On the contrary, if air enters there will be open channel flow, because the channel is so steep that an excess of heat is produced. The result is an over-size cross-section. These two possibilities, either negative $p$ or open channel flow (with $p=0$ ) occur when the bed is steep and the ice is thin, and we can speculate that suction may prevail through part of the year but terminate in the autumn when the channels start to "dry out". This might explain why hanging glaciers become more active at the end of summer. The dotted lines in Figure $5 \mathrm{~b}$ represent the hydraulic grade lines when there is open channel flow in the lower part of the ice wedge. 
Another interesting condition arises when the hydraulic grade line reaches the waterequivalent line and rises above it (Fig. $5 \mathrm{f}$ ), that is to say when $p \geqslant P$. If the conduit is located at the bottom of the ice body, $p=P$ obviously means that the water pressure equals the overburden of the ice and that the ice body is afloat or the water flows in a sheet. The theory of flow in a conduit is therefore not applicable for a further increase of $x$. However, if the conduit is entirely surrounded by ice, the water pressure can locally be higher than the hydrostatic pressure of the ice, in which case the conduit will expand. A constant diameter must nevertheless be maintained in spite of the expansion, because of the basic equilibrium assumption used to develop the equation. The physical meaning can only be that ice accretion occurs on the conduit wall. This is the case when the frictional energy
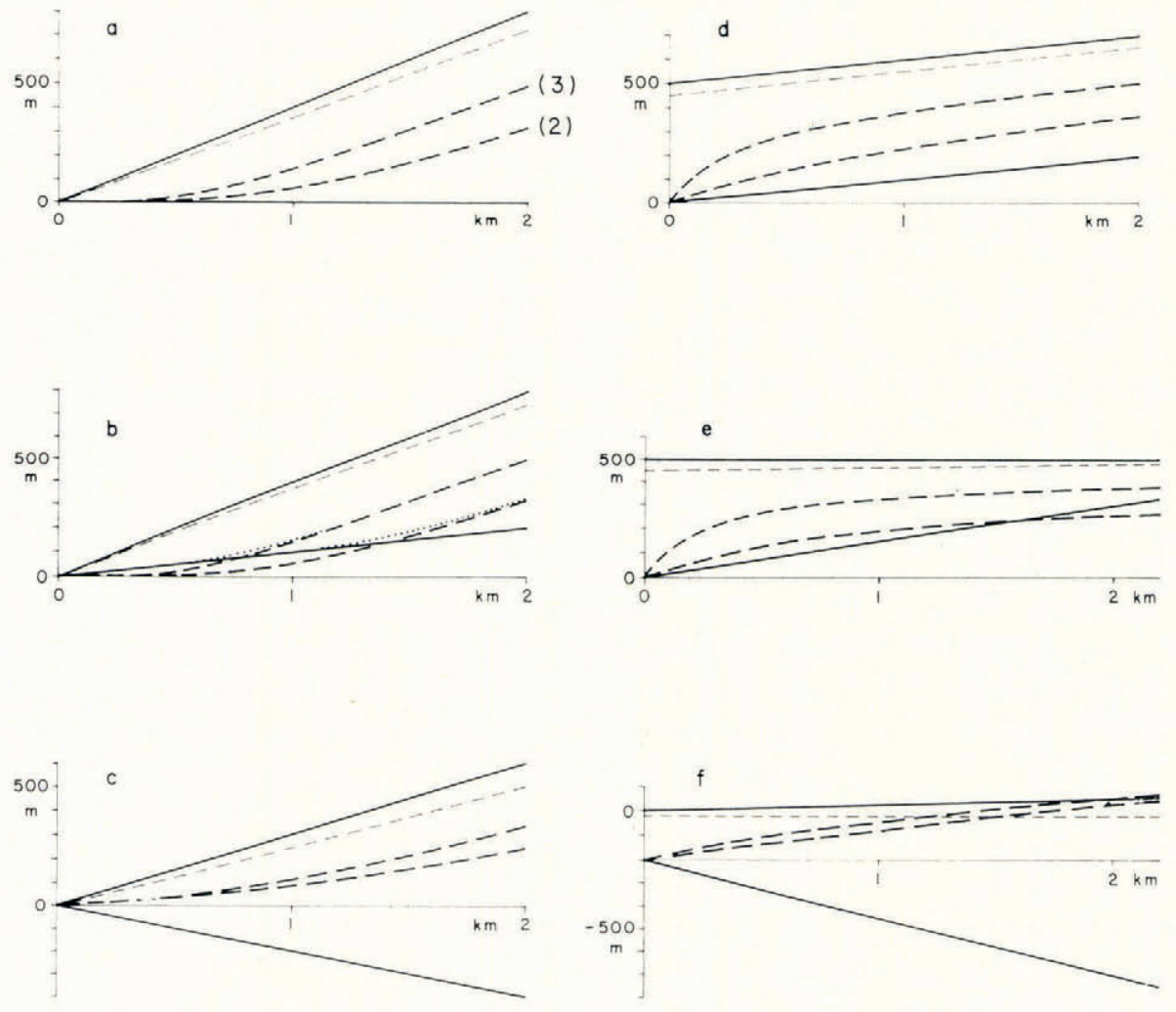

Fig. 5. Hydraulic grade lines of some model cases with constant discharge.

does not suffice to heat up the water to equilibrium temperature: part of the necessary energy has to be provided by the latent heat of freezing. That this process may occur in nature is supported by a field observation made by the author where it could be seen that ice necks had formed around small water spouts spurting out at the surface of the snout of the Griesgletscher in early summer, when the rim of the glacier was frozen to the ground.

The general trend of the curves of Figure 5 remains to be discussed. A common feature of all cases, which have a linear change of $P$ in common, is that the hydraulic grade lines tend to become parallel to the water-equivalent line. It appears that $\mathrm{d} p / \mathrm{d} x \simeq \mathrm{d} P / \mathrm{d} x$ holds for large $x$, where $\mathrm{d} P / \mathrm{d} x=$ constant, the known rate of change of $P$. If we replace $\mathrm{d} p / \mathrm{d} x$ by $\mathrm{d} P / \mathrm{d} x$ in Equation (20), the left side becomes constant, therefore the right side must 
also be constant, and the limiting value $\left(P-p_{1 \mathrm{im}}\right)$ is readily obtained giving the pressure difference between water-equivalent and hydraulic grade line for large $x$. The equation for the parallel line to the water-equivalent line determined this way satisfies Equation (20) independently of $x$, but not in general the boundary condition that $p=0$ for $x=0$. The line is presumably an asymptote (or possibly a tangent) to the hydraulic grade line.

A very simple equation is obtained for $p_{\text {lim }}$ in the case of an inclined sheet of uniform thickness (Fig. $5 \mathrm{~d}$ ), where $P=$ constant, i.e. $\mathrm{d} p / \mathrm{d} x=\mathrm{d} P / \mathrm{d} x=0$. It is

$$
p_{\lim }=P-D^{-1 / n} k^{3 / 4 n} n A Q^{1 / 4 n}\left(\rho_{\mathrm{w}} g \sin \beta\right)^{11 / 8 n} .
$$

This equation implies that $P-p_{\text {lim }}>0$ if $\beta>0$ for any positive value of $n$, which means that an ice sheet is nowhere afloat on an inclined bed, i.e. that water moves in channels rather than in a sheet, unlike the horizontal case for $n<$ I I $/ 8$. We may now ask for the condition that suction or open-channel flow occurs, i.e. that $p<0$. This is the case when

$$
P>D^{-1 / n} k^{3 / 4 n} n A Q^{1 / 4 n}\left(\rho_{\mathrm{w}} g \sin \beta\right)^{11 / 8 n},
$$

or

$$
\rho_{\mathrm{w}} g \sin \beta>D^{8 / 11} k^{-6 / 11}(n A)^{-8 n / 11} Q^{-2 / 11} P^{8 n / 11} .
$$

Likewise the condition can be stated which has to be fulfilled for a wedge of the type of Figure $5 \mathrm{c}$ to be "afloat", i.e. that $p=P$. This must be so independently of $x$, therefore $\mathrm{d} p / \mathrm{d} x=\mathrm{d} P / \mathrm{d} x$, and taking into consideration that $\beta$ is negative, Equation (20) becomes

$$
\left(\frac{\mathrm{d} P}{\mathrm{~d} x}-\rho_{\mathrm{w}} g \tan \beta\right)^{1 \mathrm{II} / 8}-0.3 \mathrm{I} 6\left(\frac{\mathrm{d} P}{\mathrm{~d} x}-\rho_{\mathrm{w}} g \tan \beta\right)^{3 / 8} \frac{\mathrm{d} P}{\mathrm{~d} x}=0 .
$$

There are two solutions,

$$
\left(\frac{\mathrm{d} P}{\mathrm{~d} x}-\rho_{\mathrm{w}} g \tan \beta\right)^{3 / 8}=0
$$

and

$$
0.684 \frac{\mathrm{d} P}{\mathrm{~d} x}-\rho_{\mathrm{w}} g \tan \beta=0 .
$$

The first one is the trivial case that $\mathrm{d} f / \mathrm{d} x=0$. The hydraulic gradient is zero, there is no flow. The hydraulic grade line, being identical with the water-equivalent line by definition, is horizontal. This is the static case of an ice body being truly afloat. The second solution gives

$$
P={ }^{1} .46 \rho_{\mathrm{w}} g(\tan \beta) x .
$$

$P$ can also be expressed in terms of $\alpha$ and $\beta$ by

$$
P=x \rho_{\mathrm{w}} g \tan \beta+x \rho_{\mathrm{i}} g \tan \alpha .
$$

Combining Equations (23) and (24) yields the following relation between $\alpha$ and $\beta$ :

$$
\tan \alpha=0.46 \frac{\rho_{\mathrm{w}}}{\rho_{\mathrm{i}}} \tan \beta=0.59 \tan \beta .
$$

If $\alpha$ is larger than that, then the hydraulic grade line is located below the water-equivalent line, as illustrated in Figure $5^{c}$. In the case of smaller $\alpha$ there would be $p>P$, but this is not possible because the ice wedge would be lifted up and become floating. However, the hydraulic gradient not being zero, the water would then rapidly disappear. It is therefore not correct in this case when we have a hydraulic gradient to speak of the ice body of being "afloat". What one can expect to happen is that the water spreads out at the contact between ice and rock and moves in a thin film, or sheet, in the way Weertman (1964, 1969) has anticipated water to move in general at the base of a glacier. As we can now appreciate, the conditions that this happens in the steady state are rather limited. 


\section{Vertical Gircular conduits}

In a vertical conduit the integration has to be carried out along the $z$-axis instead of the $x$-axis, and Equation (20) is replaced by

$$
\left(\frac{\mathrm{d} p}{\mathrm{~d} z} \pm \rho_{\mathrm{w}} g\right)^{\mathrm{II} / 8}-0.3 \mathrm{I} 6\left(\frac{\mathrm{d} p}{\mathrm{~d} z} \pm \rho_{\mathrm{w}} g\right)^{3 / 8} \frac{\mathrm{d} p}{\mathrm{~d} z}=D k^{-3 / 4}(n A)^{-n} Q^{-\mathrm{I} / 4}(P-p)^{n} .
$$

The function $P(z)$ is given by the expression $P=P / \mp \rho_{i} g z$, where $P_{0}$ is the overburden pressure at $z=0$. The upper signs are used when the water is descending, the lower ones when it is ascending; positive $z$ is taken in the opposite direction of the flow of water in accord with the previous convention for the $x$-axis. In terms of $\mathrm{d} f / \mathrm{d} z$ and $f=p \pm \rho_{\mathrm{w}} g z$, the differential equation reads

$$
\left(\frac{\mathrm{d} f}{\mathrm{~d} z}\right)^{\mathrm{II} / 8} \pm 0.462 \rho_{\mathrm{w}} g\left(\frac{\mathrm{d} f}{\mathrm{~d} z}\right)^{3 / 8}=\frac{D}{0.684} k^{-3 / 4}(n A)^{-n} Q^{-1 / 4}(F-f)^{n}
$$

with $F=P_{0} \pm\left(\rho_{\mathrm{w}}-\rho_{\mathrm{i}}\right) g z$ and $F-f=P-p$ as before. In vertical conduits the (known) gravitational term can be many times larger than the unknown frictional one, so it is more appropriate to compute the latter directly using Equation (26a). The same is true for Equation (2ob) in the case of steeply inclined conduits.

The numerical results for a few examples of vertical conduits are given in Figure 6, where the hydraulic grade line is illustrated by piezometric heights at various depth below the water line in the conduit. There is a remarkable difference between the hydraulic gradient of the case where the water is descending and that where it is ascending. In the

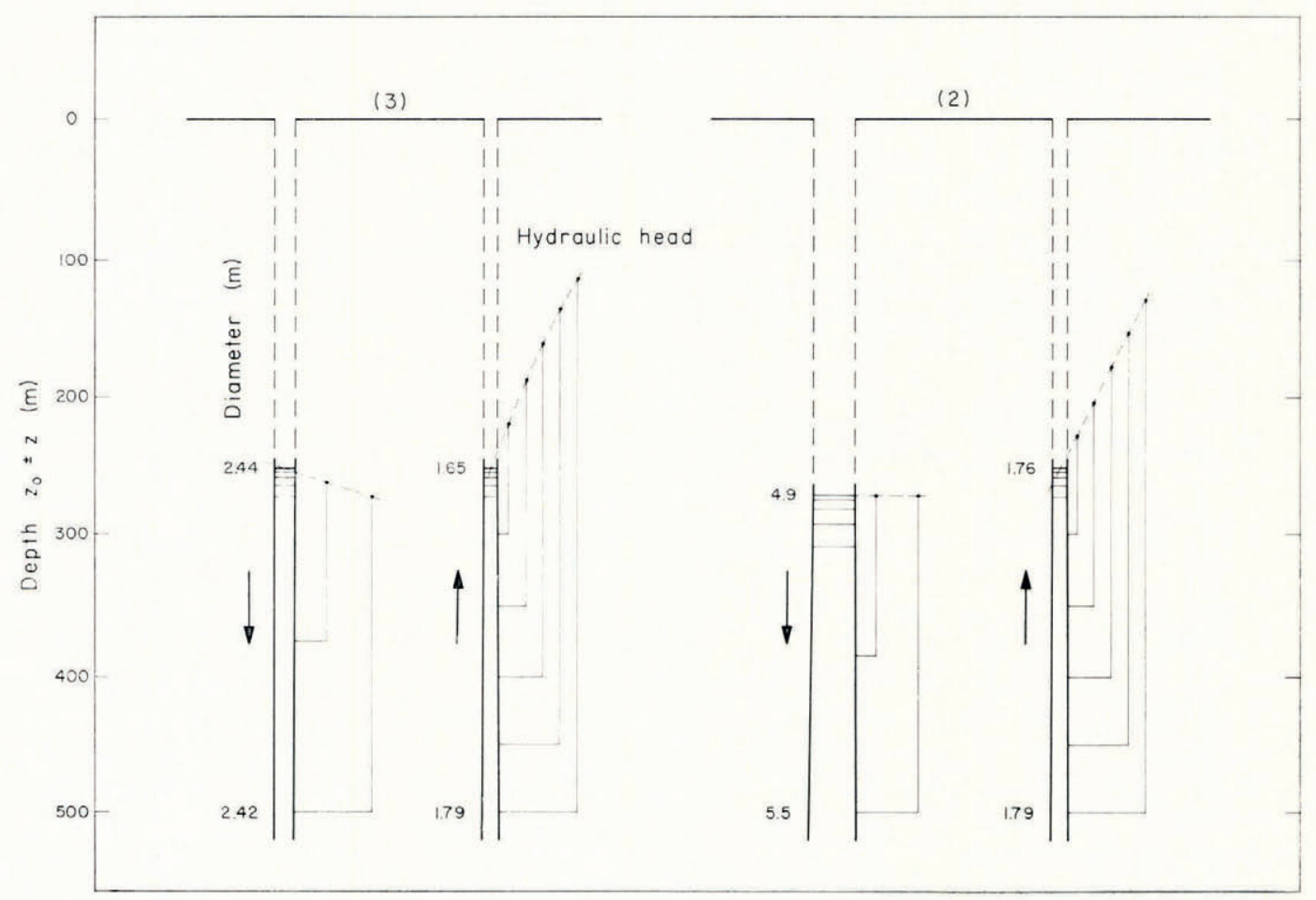

Fig. 6. Piezometric heights along vertical conduits when water is moving at a rate of $10 \mathrm{~m}^{3} \mathrm{~s}^{-1}$ between the depth of 250 and $500 \mathrm{~m}$ either downward or upward. The relative size of the conduits is also shown, and the diameters are given by numbers. The numbers (2) and (3) refer to conduit and ice parameters of Table $I$. 
latter case the gradient is many times larger. This is because energy is gained by cooling to equilibrium temperature when water descends, while energy is lost when water rises. It will be shown later that vertical links in a sub- or intraglacial hydraulic system may act in a similar way to valves.

The numbers in Figure 6 also show the change in diameter with depth as well as the much larger variation of the diameter from one case to the other.

\section{Channels at The hydraulic grade line (GRAdient conduits)}

It is conceivable that a conduit follows its own hydraulic grade line, i.e. that any piezometer installed along its course reads zero. (It is thereby assumed that the complete crosssection still carries water.) Although such a channel could hardly prevail in the middle of a glacier because of the ice movement, it might exist alongside a valley glacier in a lateral position, as pointed out later. For the following discussion it is however more convenient to refer to the new channel as being located above the bed in order to use the previous twodimensional model. From the condition that $p=0$ at all points it follows immediately that $\mathrm{d} p / \mathrm{d} x=\mathrm{o}$ throughout. The slope of the channel is the hydraulic gradient $\tan \varphi$ by definition, and for brevity the term gradient conduit will be introduced for such a channel. Replacing the angle $\beta$ by $\varphi$ in Equation (20) and observing the above conditions for $p$ and $\mathrm{d} p / \mathrm{d} x$ leads to

$$
\left(\rho_{\mathrm{w}} g \sin \varphi\right)^{1 \mathrm{I} / 8}=D k^{-3 / 4}(n A)^{-n} Q^{-1 / 4} P^{n} .
$$

From Figure 4 it is seen that the ice thickness above the new conduit is $(S-u)$, therefore $P=\rho_{\mathrm{i}} g(S-u)$. Differentiation gives

$$
\begin{gathered}
\frac{\mathrm{d} P}{\mathrm{~d} x}=\rho_{\mathrm{i} g} g\left(\frac{\mathrm{d} S}{\mathrm{~d} x}-\frac{\mathrm{d} u}{\mathrm{~d} x}\right)=\rho_{\mathrm{i}} g(\tan \alpha-\tan \varphi), \\
\tan \varphi=\tan \alpha-\frac{\mathrm{I}}{\rho_{\mathrm{i}} g} \frac{\mathrm{d} P}{\mathrm{~d} x} .
\end{gathered}
$$

By eliminating $\varphi$ between Equations (27) and (28), a relation between $\mathrm{d} P / \mathrm{d} x$ and $P$ is obtained. Integration of the differential equation thus obtained gives $P$, and thereby the channel position $u$, as a function of $x$. The relation between $\mathrm{d} P / \mathrm{d} x$ and $P$ is independent of the total ice thickness $H$ at the bed. Therefore the channel position is also independent of the bed. It depends only on the surface configuration of the glacier (besides the discharge, channel characteristics and ice characteristics).

For reasons of comparison with former results the equations will now be expressed in terms of pressure at the glacier bed. The slope of the bed is $\beta$. The ice thickness is $H$ and the height of the gradient conduit above the bed is $h$. The ice pressure is given by $P^{\star}=\rho_{\mathrm{i}} g H$, the water pressure (in a fictional vertical tube to the bed) by $p^{\star}=\rho_{\mathrm{w}} g h$. The overburden pressure at the channel is now expressed by

$$
P=\rho_{\mathrm{i}} g(H-h)=P^{\star}-\frac{\rho_{\mathrm{i}}}{\rho_{\mathrm{w}}} p^{\star} .
$$

Substitution in Equation (27) gives

$$
\sin \varphi=\frac{\mathrm{I}}{\rho_{\mathrm{W}} g} D^{8 / 11} k^{-6 / 11}(n A)^{-8 n / \mathrm{II}} Q^{-2 / 1 \mathrm{I}}\left(P^{\star}-\frac{\rho_{\mathrm{i}}}{\rho_{\mathrm{W}}} p^{\star}\right)^{8 n / \mathrm{II}},
$$

whereas

$$
\tan \varphi=\frac{\mathrm{d} Z+\mathrm{d} h}{\mathrm{~d} x}=\tan \beta+\frac{\mathrm{I}}{\rho_{\mathrm{w}} g} \cdot \frac{\mathrm{d} p^{\star}}{\mathrm{d} x} .
$$


Eliminating $\varphi$ between Equations (30) and (3I) leads to

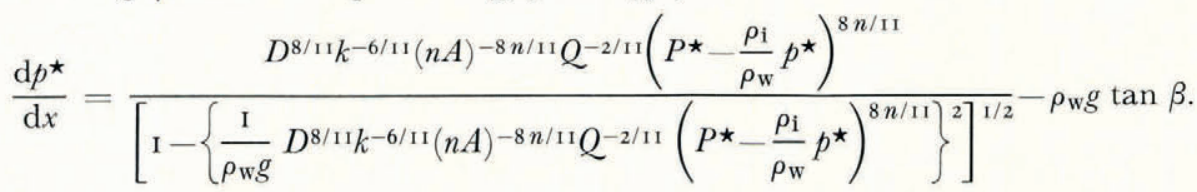

This equation has served to find $p^{\star}$ by numerical integration in the same way as Equation (20) was used to compute $p$, with $k, n, A$ as constants and $Q, P^{\star}$ and $\tan \beta$ as functions of $x$.

Even for the simple case of a horizontal ice sheet of uniform thickness and constant $Q$, no explicit solution exists. But in writing $\tan \varphi=\epsilon \sin \varphi$ where $\epsilon$ varies between I and $(\mathrm{I} / 0.684)^{8 / \mathrm{II}}=\mathrm{I} \cdot 3 \mathrm{I} 8$ for values of $\varphi$ not exceeding $40.6^{\circ}$, we obtain

$$
\begin{gathered}
\int \frac{\mathrm{d} p^{\star}}{\left(P^{\star}-\rho_{\mathrm{i}} p^{\star} / \rho_{\mathrm{W}}\right)^{8 n / \mathrm{II}}}=\epsilon D^{8 / \mathrm{II}} k^{-6 / \mathrm{II}}(n A)^{-8 n / \mathrm{II}} Q^{-2 / \mathrm{II}} \int \mathrm{d} x ; \\
x=\frac{\mathrm{II}}{8 n-\mathrm{II}} \cdot \frac{\rho_{\mathrm{W}}}{\rho_{\mathrm{i} \epsilon}} D^{-8 / \mathrm{II}} k^{6 / \mathrm{II}}(n A)^{8 n / \mathrm{II}} Q^{2 / 1 \mathrm{II}} P^{-(8 n-\mathrm{II}) / \mathrm{II}}\left[\left(\mathrm{I}-\frac{\rho_{\mathrm{i}}}{\rho_{\mathrm{W}}} \cdot \frac{p^{\star}}{P^{\star}}\right)^{-(8 n-11) / \mathrm{II}}-\mathrm{I}\right] .
\end{gathered}
$$

This equation is used in the following section for comparison with previous findings.

\section{Position OF CONDUits WITHIN THE GLAGieR}

Let us first assume an inclined hole in a mass of ice with a horizontal surface. The hole will be partly filled with water at rest. The pressure difference $P-p$ is then greatest at the water level and decreases with depth because of the density difference between ice and water. The hole would therefore close more rapidly at the water level than deeper down, and at first sight it seems logical to conclude that water would tend to flow at a level as deep as possible, i.e. in a valley glacier in a main water channel along the thalweg. In order to test this assumption for flowing water, two extreme channels will be compared with each other in the simple case of the horizontal ice sheet of uniform thickness. The channels compared are the one at the bottom and the one at the hydraulic grade line. For these, the relations between distance $x$ and pressure are expressed in Equations (I2) and (34). The ratio of the values of $x$ given by the two equations gives the ratio of the distances at which the piezometer pressure is equal in both conduits if $p=p^{\star}$. For $n=3$ it is:

$$
\frac{x_{\text {gradient }}}{x_{\text {bottom }}}=\frac{\rho_{\mathrm{W}}}{0.684^{8 / 11} \epsilon \rho_{\mathrm{i}}} \cdot \frac{\left(\mathrm{I}-\rho_{\mathrm{i}} p / \rho_{\mathrm{W}} P\right)^{-13 / 1 \mathrm{I}}-\mathrm{I}}{(\mathrm{I}-p / P)^{-13 / 1 \mathrm{I}}-\mathrm{I}} .
$$

Let us first assume that $p / P \ll \mathrm{I}$, then

$$
\frac{x_{\text {gradient }}}{x_{\text {bottom }}} \simeq \frac{\mathrm{I}}{0.684^{8 / \mathrm{II}} \epsilon} \geqslant \mathrm{I}, \quad \text { for } \varphi \leqslant 40.6^{\circ} .
$$

This means that at short distances from the portal a certain piezometer pressure is reached in the bottom channel at a shorter distance than in the gradient channel, i.e. that the hydraulic grade line of the bottom channel rises above the gradient conduit. Consequently flow in the gradient channel would be the more stable condition. For long distances, where $0 \ll p \mid P<\mathrm{I}$ the opposite is true, since $x_{\text {gradient }} / x_{\text {bottom }} \simeq \mathrm{o}$, if $p \mid P \simeq \mathrm{r}$.

These findings are confirmed by the numerical results presented in Figure 7 , where the hydraulic grade lines of cases (I), (2) and (4) of Figure 2 (solid lines) are compared with the positions of channels at the hydraulic grade (dashed lines). The dashed lines lie below the solid ones in the lower part of the curves, but rise above higher up. It is not difficult to explain this behaviour. At the beginning the bottom channel shows a larger hydraulic gradient because of the additional heat which must be produced for temperature adjustment (with the exception of very large gradients where the gradient channel becomes 
sufficiently longer than the bottom one because of the great slope). At large distances, however, the pressure head for the bottom conduit approaches the water-equivalent, while the gradient channel, not being dependent on ice depth, ultimately reaches the surface.

The fact that the gradient channel is, for a fair distance (I I $\mathrm{km}$ for cases (2) in Fig. 7), lower than the hydraulic grade line of the bottom conduit, is of considerable importance, since it seems to suggest that water should flow at the grade line rather than at the bottom. In a valley glacier the gradient channels would probably not be located in an arbitrary position somewhere in the glacier, but most likely along the borders. Since that is where large amounts of water are collecting, there is little doubt that lateral channels must exist. Nevertheless, the analysis shows also that water can circulate at deeper levels, in particular at the thalweg, at sufficient distance from the portal. It can easily penetrate to that depth as illustrated by the small hydraulic gradient of vertically descending water (Fig. 6). The question which now arises is whether or not water, once at the bottom, may well up again

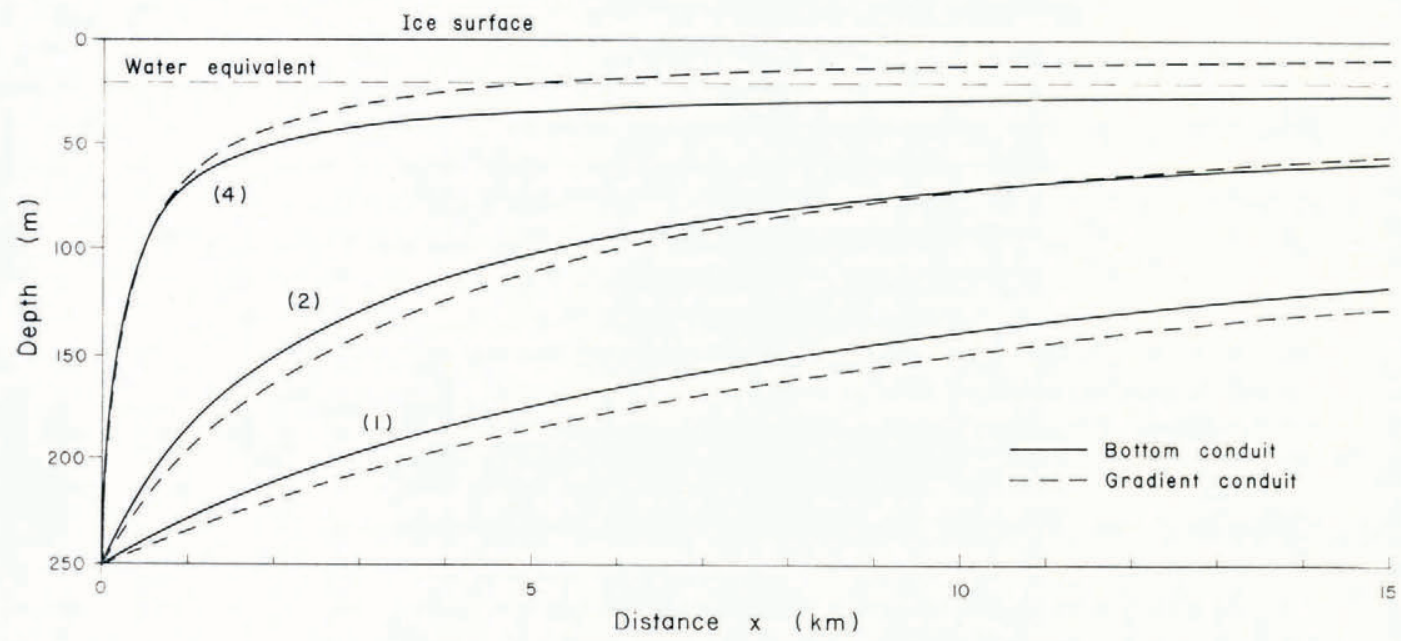

Fig. 7. Comparison of the hydraulic grade line of a bottom conduit (solid lines) with the position of the gradient conduit following its own grade line (dashed lines) in a horizontal ice sheet $250 \mathrm{~m}$ thick for various assumptions of conduit and ice characteristics according to Table I.

to the hydraulic grade line further down the glacier. Since it would have to flow from high to low hydrostatic pressure, the hydraulic gradient would have to be relatively large to provide the necessary energy for heating the water. In the example presented in Figure 6 together with Figure 7 it can be shown that the pressure difference necessary to keep a vertical conduit open by ascending water is far greater than the pressure difference between gradient and basal channels. Even if a hole were drilled and the water could originally move through it, the hole would close again in time. Since water may pass downward through an inclined (vertical) conduit at the upper reaches of the glacier, but not keep the connection open in the lower part, the ice barrier between channels at different levels seems to act like a valve letting water pass more easily in the downward direction.

Only one interpretation is finally possible, namely that both types of channels, those at the bottom and those at the hydraulic grade line - the latter ones probably in a lateral position - may legitimately exist. Whether some intermediate position, like a straight line from the glacier head to the portal, would be even more favourable has not been investigated. 


\section{Shape OF CROSS-SEction OF BOTTOM CHANNELS}

Since the important formulas presented above are based on the closure of a cylindrical hole by radial ice flow from all sides towards the axis they cannot directly be applied to a channel at the glacier bed. An attempt will therefore be made to approach the conduit at the boundary by a different model, consisting of a semi-circular tunnel in the ice with a flat bottom at the glacier bed.

The closure rate of the half circle is the same as for the full one if the friction of the ice on the ground is neglected, but the different shape of cross-section causes more resistance for the flowing water and therefore a larger hydraulic gradient. Developing an equation analogous to Equation (II), but using $V_{\mathrm{c}}=r \pi \dot{r} \mathrm{~d} x$ for the closure by volume and $R=\pi r /(2 \pi+4)$ for the hydraulic radius, the expression

$$
B^{\prime}=\frac{2^{12 / 1 \mathrm{II}}(2+\pi)^{4 / 11}}{\pi^{2 / 1 \mathrm{I}}}\left(\frac{c_{\mathrm{m}} \rho_{\mathrm{i}}}{0.684}\right)^{8 / \mathrm{II}}\left(\rho_{\mathrm{W}} g\right)^{3 / \mathrm{II}}
$$

is obtained in place of $B$, so that $B^{\prime}=1.196 B$. It shows that the hydraulic gradient is larger by some $20 \%$ for a basal semi-circular horizontal conduit than for a circular one entirely within the ice, so that from this argument alone water would be expected to flow above the bed. This is even more so because a channel on the ground will be rougher than one completely in ice. However, to neglect the bottom friction of ice is not admissible. Qualitatively speaking a restricted ice flow can only mean that less heat is needed to keep the channel open. The result is a reduction of the hydraulic gradient contrary to the other bottom effects. To apply the equations for conduits of circular cross-section surrounded by ice to differently shaped channels at the lower ice boundary may not be very wrong after all. In view of the uncertainty of ice properties and further complications to be discussed later, like erosion into the bed or sedimentation, it would not seem justified to apply more sophisticated theory to the boundary effects at this stage.

\section{Computed AND OBSERved WATER pressure at THE Bed of the Gornergletscher}

A suitable example to test the methods of computation has been found in the Gornergletscher, for which some unique information has become available in relation with the Grande Dixence power project (Bezinge and others, in press). Not only is the bedrock topography known in great detail, but the Gornergletscher is also one of the very few glaciers on Earth where subglacial water pressures have actually been measured. The longitudinal profile through the tongue, based on seismic soundings and drilling results, is given in Figure 8 (bottom). It has been used to draw a simplified model of the glacier by approximating the bed and surface profiles by polygons (top of Figure 8). The origin of the distance scale is chosen where a syphon* of the Grande Dixence scheme crosses the glacier. This is the site where the water pressure has been measured by means of manometers in three holes drilled from the power tunnel upwards through the rock to the glacier bed above.

The pressure measurements are not easy to interpret, but it seems admissible to use only that part of the results which agrees best with the basic condition of the model, i.e. the steady state. A fairly stable water head of about $60-70 \mathrm{~m}$ above the bedrock persisted from May till July of 1960 , and the head of $60 \mathrm{~m}$ has subsequently been used as the basis for the computations, together with a discharge figure of $10 \mathrm{~m}^{3} \mathrm{~s}^{-1}$. The discharge of the torrent leaving the glacier at the time was of this order, with variations from 4 to $20 \mathrm{~m}^{3} \mathrm{~s}^{-1}$.

The period of stable pressure came to an abrupt end in late July, when, after a sharp peak in the discharge, the water head dropped close to the glacier bed in two out of three

"An "inverted syphon" in proper terms. 
holes. The reason is not known, but it is conceivable that warm water had penetrated along the edge of the glacier, lowering one of the lateral channels all the way to the bottom of the ice. In any case something irregular seems to have happened, which may well be neglected in the adjustment of the theory to the observations.

There are further complications, indicated in the longitudinal profile of Figure 8 by a discrepancy between seismic soundings and drilling. The lower boundary is the one obtained by the rock drilling from the power tunnel, and it represents the interface between bedrock and a basal moraine layer. Whether the ground moraine is only a few metres thick as shown by drillings near the edge, or whether it extends all the way to the seismic horizon is not
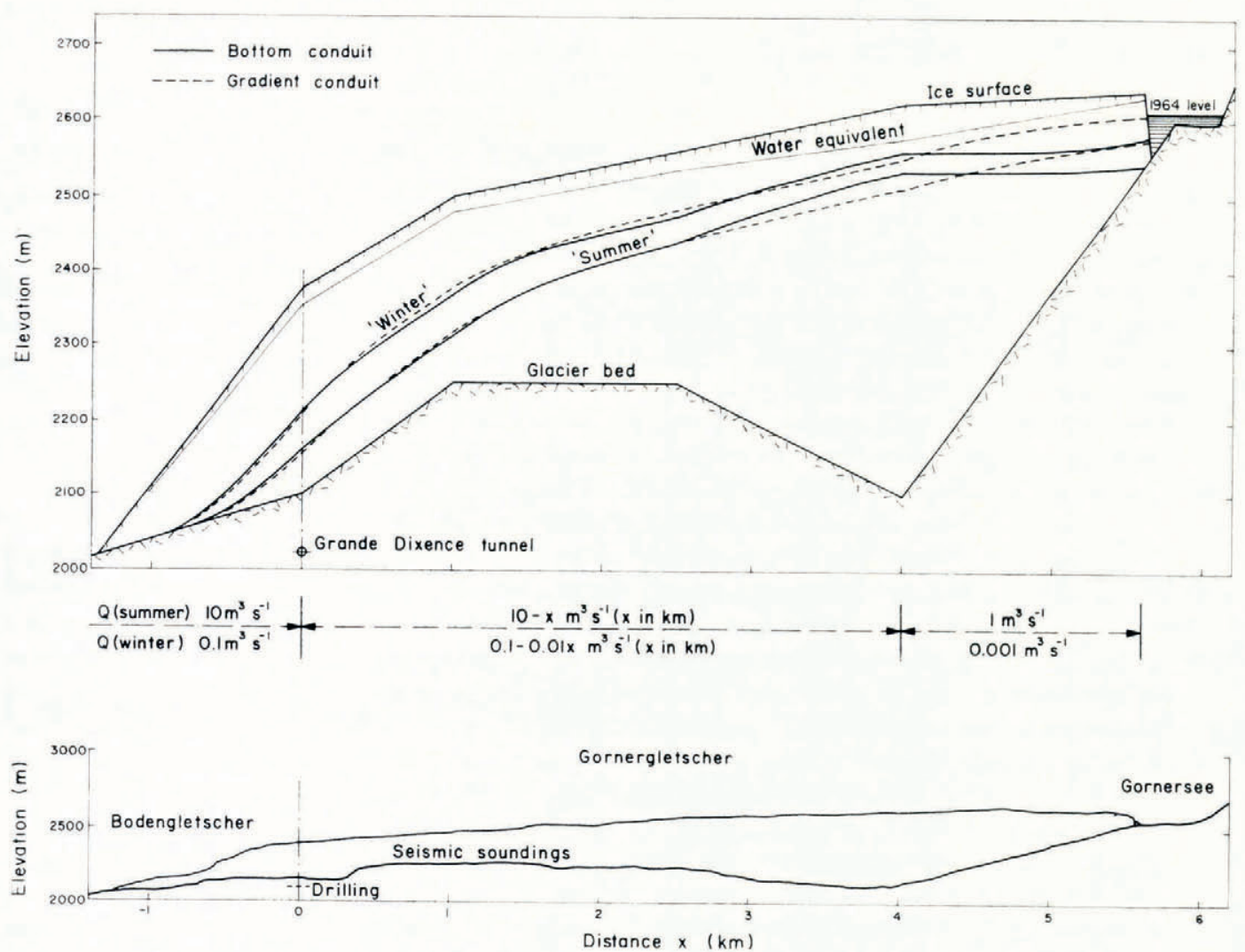

Fig. 8. Top: Longitudinal profile of the Gornergletscher model for computation, with resulting hydraulic grade lines for high and low discharge. Bottom: Natural longitudinal profile.

known. Previous thermodrill soundings from the glacier surface have stopped at a level comparable to the seismic, and the water emptied from the holes, so that a permeable layer appears to exist some 50 to $80 \mathrm{~m}$ above the rock bed even if the intermediate layer between seismic and drilling horizon should consist mainly of ice. It probably does, otherwise the sudden pressure drop of late July ig6o would be hard to understand. The bedrock depth as shown by the rock drilling has been used to draw the idealized profile.

The snout of the glacier below the Grande Dixence tunnel is represented in the idealized profile by a wedge. A hydraulic grade line had to be found to approximate the value of $60 \mathrm{~m}$ at $\mathrm{km} \mathrm{o}$, ending tangentially at the bed at some unspecified distance below. This was done by a trial and error process, varying the combined factors of conduit roughness and 
ice flow properties, using a discharge figure of $10 \mathrm{~m}^{3} \mathrm{~s}^{-1}$. Assuming a very rough bed the value of $A$ of case (3) in Table I was obtained. The resulting hydraulic grade line is shown in Figure 8 by the solid line indicated "summer". For the continuation of the line at greater distances, a decrease in discharge of $\mathrm{I} \mathrm{m}^{3} \mathrm{~s}^{-1}$ per $\mathrm{km}$ from $\mathrm{km}$ o to 4 , from ro to $6 \mathrm{~m}^{3} \mathrm{~s}^{-1}$, and a constant discharge of $\mathrm{I} \mathrm{m}^{3} \mathrm{~s}^{-1}$ for the steeply inclined bed beyond $\mathrm{km} 4$ have been assumed. The much smaller discharge in the last section is attributed to a stream which has its source in the Gornersee and joins the two main bottom streams from the Gornergletscher and Grenzgletscher in the deepest point of the depression at $\mathrm{km} 4$ - at the junction of the two main glacier branches forming together the Gorner tongue. The lake is located in the corner of the junction (Bezinge and others, in press).

A second solid line is shown in Figure 8 marked "winter". This is the hydraulic grade line obtained with low discharge figures, namely $0.1 \mathrm{~m}^{3} \mathrm{~s}^{-1}$ below $\mathrm{km} \mathrm{o}$, between o.I and $0.06 \mathrm{~m}^{3} \mathrm{~s}^{-1}$ linearly decreasing at the rate of $0.01 \mathrm{~m}^{3} \mathrm{~s}^{-1} \mathrm{~km}^{-1}$ from $\mathrm{km}$ o to 4 , and $0.00 \mathrm{I} \mathrm{m}^{3} \mathrm{~s}^{-1}$ between $\mathrm{km} 4$ and the lake. Comparing the results for the winter and summer conditions with each other it is seen that the winter curve runs a few tens of meters above the summer one. Of particular interest now is the fact that the winter line rises above the lake bottom. If the theory is correct, this would give an explanation of the periodic filling and emptying of the Gorner and any similar glacial lake, because after the low water head of summer the lake will start to form again when the water system adjusts to the low winter discharge, i.e. the high hydraulic grade line. This should go on as long as the lake level stays below the winter line, but as soon as it rises above it, the lake would be ready for the next outburst. This picture is quite inaccurate to begin with, because, during the time when the lake level is below the theoretical water head in the conduit, there would be no outflow from the lake and consequently a higher hydraulic grade line would be approached for $Q \simeq 0$, unless some water moves in the reverse direction. Obviously the situation cannot be analysed satisfactorily by neglecting the time factor. However, it may be concluded that the lake level might have to rise fairly high before the outburst is triggered, although the connection in the conduit theoretically never breaks. This may be different in nature, as stressed by Bezinge and others (in press). Otherwise it would be difficult to explain why the outbreak occurs at such widely different dates. Even so, the fact remains that a periodic filling of the lake is inherent in the basic drainage theory.

For comparison the corresponding curves for the position of gradient (lateral) conduits are included in Figure 8 (dashed lines). It is seen that they end at the lake considerably above the hydraulic grade lines of the bottom conduits. This indicates that the latter ones should be operative and that the lake outlet should follow the bottom. This has been verified, at least to a certain depth. In the fall of I 969 a unique opportunity occurred to inspect the main subglacial outflow channel from the Gornersee and to observe the water level directly. After the lake had emptied on 27-28 July, a group of speleologists came across an immense pothole in the depression of the Gornergletscher adjacent to the main lake in early October. The pothole gave access to the outlet from the main lake, below the chaos of stranded icebergs at the foot of the ice cliff. It was found that the outlet channel stayed at the bottom of the ice, with moraine and rock outcrops forming the floor, as illustrated by Figure II. On 3 October the group descended to a considerable depth of approximately $90 \mathrm{~m}$ below the surface but turned back lacking proper equipment. On 22 October one of them guided a group organized by Grande Dixence under the leadership of Mr A. Bezinge, to penetrate as deeply as possible, and the author was able to participate. The second visit ended somewhat disappointingly for the participants, less so for the verification of the theory. The steeply descending tunnel was flooded some ro $\mathrm{m}$ above the lowest point reached three weeks earlier. Furthermore it was observed that the water level was slowly getting lower during the morning, but started to rise again around noon when melt water occurred at the glacier surface. Obviously the conduit was still functioning as a subglacial drainage 
channel (the short-term oscillations do not contradict the theory, because the time involved is not sufficient for the conduit to adjust to the steady-state condition).

Actually to observe the water level in a subglacial conduit in autumn at a height between the theoretical summer and winter levels of Figure 8 was more than one could have anticipated, considering the many approximations and assumptions made in the computation. Less satisfactory is the fact that no high winter pressure has been observed at the Grande Dixence syphon. However, this may be explained by the presence of the permeable ground moraine, letting part of the water filter through. A noticeable reduction of pressure is thereby to be expected at low discharge. In other cases a high winter level has indeed been observed, in particular by Vivian and Zumstein (in press) at the Glacier d'Argentière where the ice rests on a bedrock Riegel, and by Mathews (1964) in a lateral position at the South Leduc Glacier in an exploratory tunnel of a mine.

\section{VARIOUS OTHER COMPUTATIONS}

Formulas for the conduit radius $r$, the mean transit time $t$ of water running from $x_{2}$ to $x_{1}$, and kinetic energy $E_{\mathrm{k}}$ have been included in the computer programme. They are:

with

$$
r=2^{1 / 4} \pi^{-3 / 8}\left(\rho_{\mathrm{w}} g\right)^{3 / 16} k^{-3 / 8} Q^{3 / 8}\left(\frac{\mathrm{d} f}{\mathrm{~d} s}\right)^{-3 / 16}
$$

$$
\begin{gathered}
\frac{\mathrm{d} f}{\mathrm{~d} s}=\frac{\mathrm{I}}{\cos \beta}\left(\frac{\mathrm{d} p}{\mathrm{~d} x}+\rho_{\mathrm{w}} g \tan \beta\right) ; \\
\bar{t}=\int_{x_{1}}^{x_{2}} \frac{\mathrm{d} s}{\bar{v}}=\int_{x_{1}}^{x_{2}} \frac{r^{2} \pi}{Q} \mathrm{~d} s=\int_{x_{1}}^{x_{2}} \frac{r^{2} \pi}{Q \cos \beta} \mathrm{d} x,
\end{gathered}
$$

and

$$
E_{\mathrm{k}} \approx \frac{\rho_{\mathrm{w}} Q}{2} \bar{v}^{2}=\frac{\rho_{\mathrm{w}} Q^{3}}{2 \pi^{2} r^{4}} .
$$

As an illustration the results of computations of the diameter $2 r$ are given in Figure 9 for the previous example of bottom and gradient channels for summer and winter run-off at the Gornergletscher. From summer to winter the conduit diameters should reduce by a factor of about five. It is of some interest to see what time intervals would be needed for this to happen. The computation would become very involved if the melting by the flowing water were taken into account, but since there are sections with practically no flow in winter an estimate of closure time can at least be given for this situation. The time necessary for the conduit radius to change from $r_{1}$ to $r_{2}$ is

$$
t_{\mathrm{c}}=\left(\frac{n A}{P-p}\right)^{n} \ln \frac{r_{1}}{r_{2}} .
$$

For a five-fold diameter reduction a time interval of $3 \mathrm{I} d$ would be needed for $P-p=8$ bar (some $80 \mathrm{~m}$ depth), and $\mathrm{I} 28 \mathrm{~d}$ for $P-p=5$ bar ( $\approx 50 \mathrm{~m}$ depth), using $n=3$ and $A$ according to case (3) in Table I. In a period twice as long the conduit would reduce to $\mathrm{I} / 25^{\text {th }}$ of the original width. It is seen that a considerable closure can be expected to take place between a lake burst and the time the lake fills again in the following spring. The closure times given here are much shorter than the ones given by Haefeli (1970), because of the different value of $A$.

A less satisfactory result has been obtained with the computation of travel time (Fig. Io). The surprising thing is the excessive shortness of $\bar{t}$, in particular for the summer discharge. The total flow time from the Gornersee to the portal has come out at about $3 \mathrm{~h}$, while Bezinge and others (in press) have concluded that the water takes about $\mathrm{I} 2 \mathrm{~h}$ in the initial 


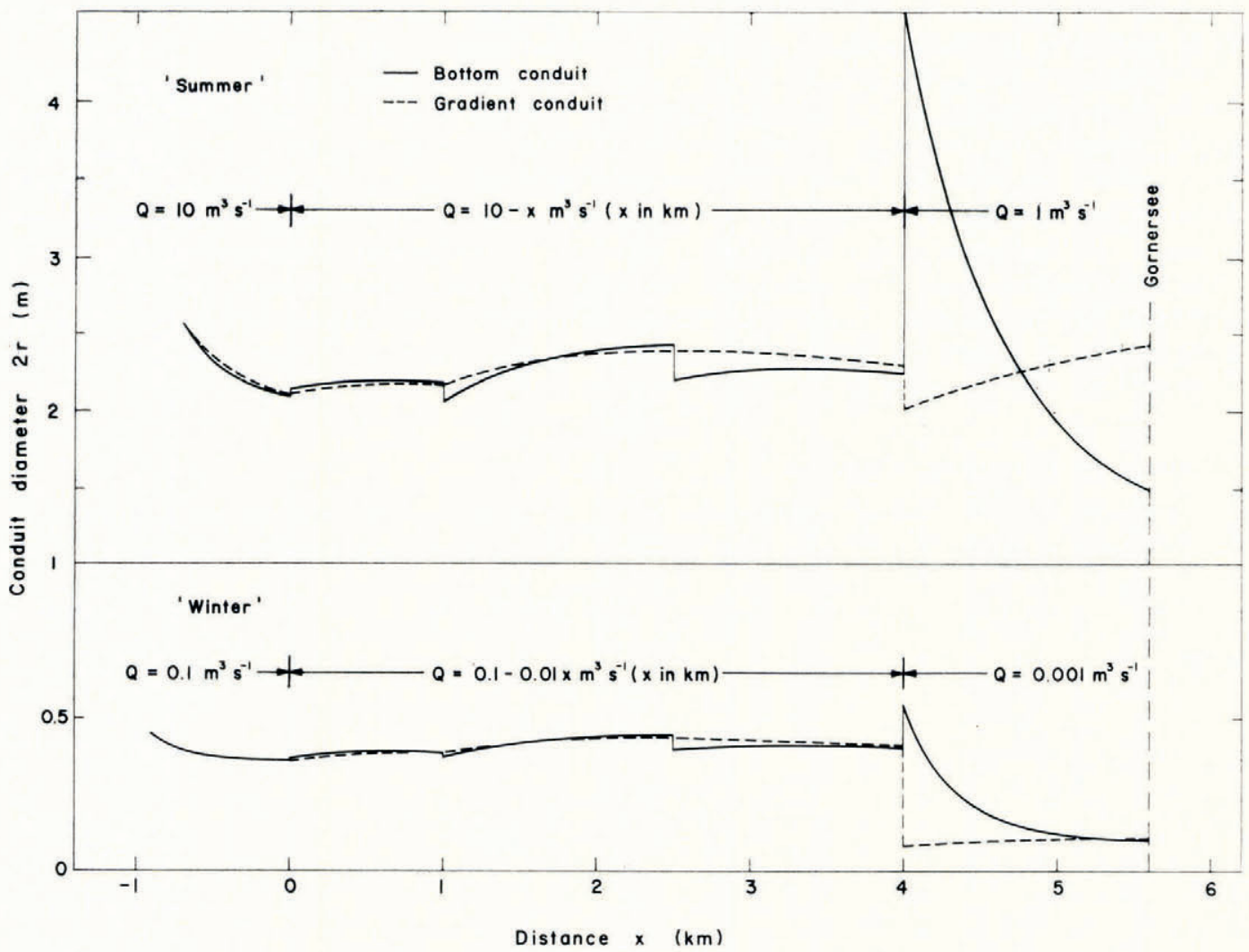

Fig. 9. Conduit diameters for the Gornergletscher model of Figure 8.

stage of the lake burst.* The computed figure obtained with the channel roughness of an ordinary torrent thus does not seem to fit the conditions for a subglacial water course. This will be further discussed below together with various other complications to be expected in natural flow.

Equation (39) has merely served to check that neglecting the kinetic energy is justified.

For the case of laminar flow in the inclined circular conduit, Equation (9) is replaced by

$$
\bar{v}=\frac{r^{2}}{8 \eta} \cdot \frac{\mathrm{d} f}{\mathrm{~d} s}
$$

where $\eta=\mathrm{r} .798 \times \mathrm{IO}^{-3} \mathrm{~kg} \mathrm{~s}^{-1} \mathrm{~m}^{-1}$ is the viscosity of water at $0^{\circ} \mathrm{C}$. In analogy to Equation (20) the differential equation

$$
\begin{aligned}
\left(\frac{\mathrm{d} p}{\mathrm{~d} x}+\rho_{\mathrm{w}} g \tan \beta\right)^{3 / 2} & -0.3 \mathrm{I} 6\left(\frac{\mathrm{d} p}{\mathrm{~d} x}+\rho_{\mathrm{W}} g \tan \beta\right)^{\mathrm{I} / 2} \frac{\mathrm{d} p}{\mathrm{~d} x} \\
& =D^{\prime} \eta^{1 / 2}(n A)^{-n} Q^{-1 / 2}(\cos \beta)^{-3 / 2}(P-p)^{n},
\end{aligned}
$$

is obtained, with

$$
D^{\prime}=2^{5 / 2} \pi^{1 / 2} c_{\mathrm{m}} \rho_{\mathrm{i}}
$$

* Note added in proof: Transit times of the order of $\mathrm{I}$ to $2 \mathrm{~h}$ have nevertheless been observed with dye tracers at Hintereisferner for a comparable distance of several kilometres by Lang (1966), and his findings were recently confirmed (personal communication from W. Ambach). 
The conduit radius is now expressed by

$$
r=\left(\frac{8 \eta}{\pi}\right)^{\mathrm{I} / 4} Q^{\mathrm{I} / 4}\left(\frac{\mathrm{d} f}{\mathrm{~d} s}\right)^{-\mathrm{I} / 4} .
$$

For the numerical solution the same computer programme has been used as for the turbulent case, with different factors and exponents.

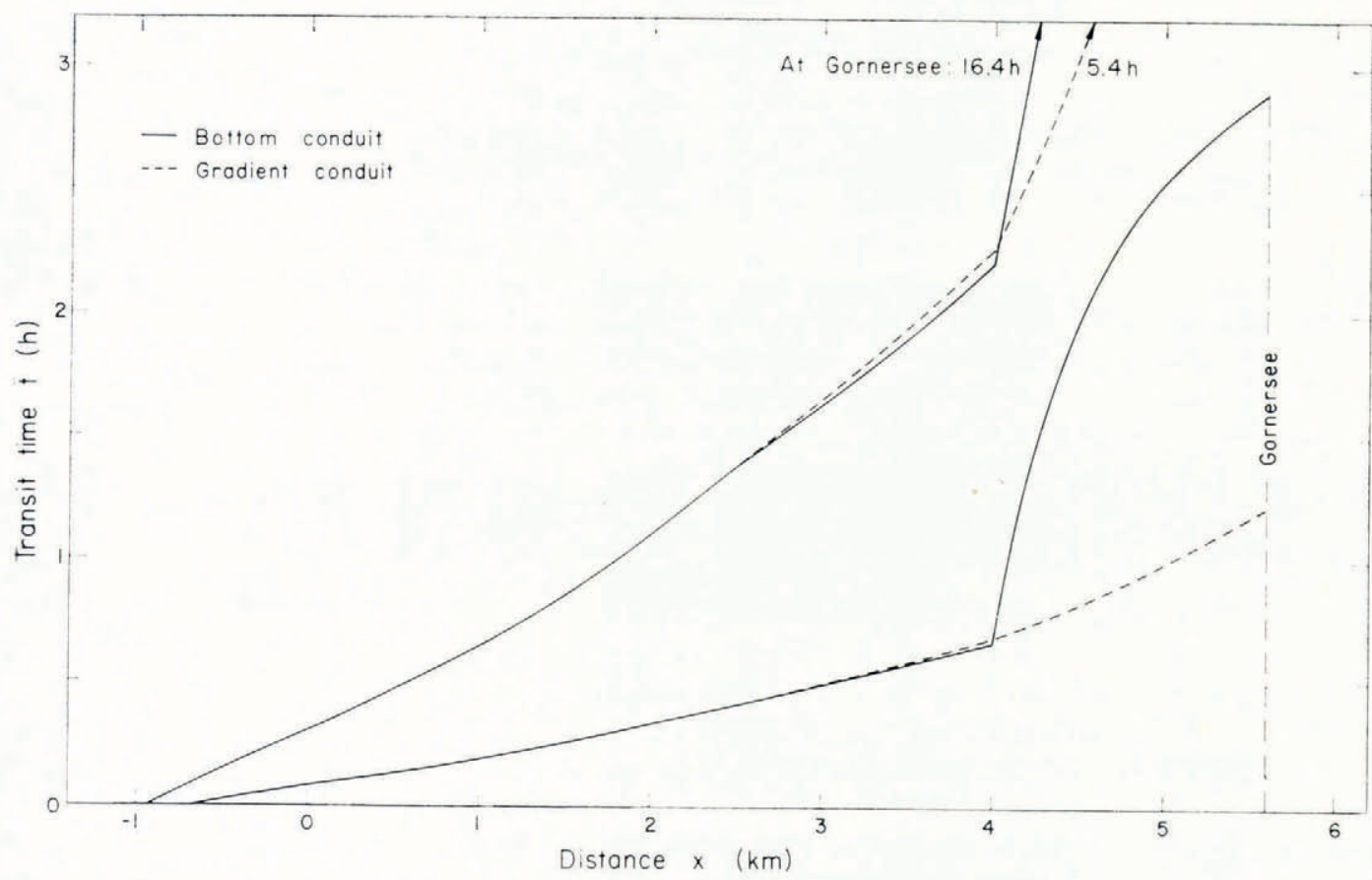

Fig. Io. Mean transit times of water for the Gornergletscher model of Figure 8. Lower curves for "summer", upper curves for "winter" flow.

LiMITATION OF THEORY AND DISGUSSION OF VARIOUS ADDITIONAL PHENOMENA INFLUENGING WATER PRESSURE

The theory presented in this paper is developed for a simple model consisting of a conduit of circular cross-section completely surrounded by ice. It is further based on the assumption of the steady state for the flow of water and the closure of the conduit by creep. Even for this simple model various approximations are made in the mathematical treatment.

First of all the kinetic energy is neglected, but this does not seem to introduce a significant error since the velocity head is only a small fraction of the hydraulic head in most practical cases. Probably less justified is the assumption of instantaneous heat transfer, at least when the conduit radius is large as in the case of large discharge. Mathews (in press) has taken the heat transfer into account in his analysis of the lake burst of Summit lake, and he has shown that in his case $10 \%$ of the heat produced in the water by friction is carried away by the water, leaving the glacier at a temperature above $0^{\circ} \mathrm{C}$, at the discharge of $5 \mathrm{~m}^{3} \mathrm{~s}^{-1}$. The corresponding figure rises to some $50 \%$ when the discharge reaches about $200 \mathrm{~m}^{3} \mathrm{~s}^{-1}$. Taking into account in our theory that the ice is melting at a channel section at some distance down-stream from where it is produced would hardly change the results in a qualitative 
way, but quantitatively the overall pressure would be somewhat higher, because less heat is available for melting ice. However, in nature most water originates at the glacier surface and has some initial drop before it reaches the water table. It is therefore likely to be at a higher temperature than the ice, and the heat exchange can take place everywhere in the conduit. An equilibrium similar to the computed one will be established, but at a higher water temperature than the pressure melting point throughout. Even so some change in the hydraulic grade line will take place. The mathematical problem for a solution taking the heat transfer into account would become more complicated, since the integration should now be carried out from the source to the portal, while it has to start at the portal to fulfill the boundary condition of zero pressure there. A solution by successive approximation would have to be sought.

The computation of the given model could be improved, but it is doubtful that much would be gained. The difficulties at this stage lie less in the mathematical treatment than, for one thing, in the uncertainty of ice properties and conduit geometry and, for another thing, in the question of how good the model is. The latter question is of particular importance, since the model shows some severe deviations from nature, such as neglecting the change of discharge with time, the flow of the glacier (in particular bed-slip), and the action of the water at the bed. These complications have to be considered for a better understanding of the theoretical results, and they will be discussed to some extent.

\section{Time-DEPEndent Discharge}

A constant discharge is one of the fundamental assumptions of the theory. It is therefore possible that the results might change profoundly if the discharge changes with time. This is undoubtedly true for quick discharge variations, while for sufficiently slow changes the conduit will adjust continuously to the new condition, and the theoretical water pressure will then be a good approximation. Let us assume a periodic change of discharge. At sufficiently long periods the previous finding that the water pressure is lowest at the highest discharge will still be true, in other words water pressure and discharge are out of phase by $180^{\circ}$. At very short periods, on the contrary, there will be no time for the conduit to adjust, and obviously pressure and discharge are in phase. The conduit diameter will correspond to a mean discharge (though not the arithmetic mean). It is now important to define what is meant by long and short periods. This depends on the time constants by which the conduit diameter adjusts to new conditions. The time constants involved are the one for an enlargement of the conduit by increased flow of water and the one for closure by creep of ice. The adjustment to increased flow of water appears to be fairly rapid, as shown by Mathews (in press) in his analysis of lake bursts, where large channels form in the matter of days. The closure rate of the conduit shows a different behaviour. It varies strongly with the pressure difference $P-p$ between overburden pressure of the ice and water pressure, and the corresponding time constant can be of the order of days as well as of the order of years. As a working hypothesis we may assume that the water pressure is approximately in phase with the discharge for diurnal, and out of phase for annual variations, except when the ice is thin. In this latter case it would take over a year for the conduit to adjust from summer to winter conditions. From this fact it is evident that the theory should not be applied to channels close to the surface, say at lesser depth than about $50 \mathrm{~m}$. Consequently the proposed mechanism for periodic filling and emptying of glacial lakes can only apply to lakes located above relatively large glaciers where the outlet penetrates to a sufficient depth. This agrees with the findings of Liestøl (1956), who has concluded from experience with glacier-dammed lakes in Norway that the outlets stay permanently open when the ice dam is less than $50 \mathrm{~m}$ thick. 
Before leaving the question of time-dependent discharge it seems worthwhile to look more closely into the question of pressure fluctuations and mean pressure. Above we have surmised that the daily variation of discharge and pressure is in phase and that the conduit diameter should remain approximately constant. If this is so then the daily pressure fluctuation can be estimated from the Gauckler-Manning-Strickler equation (I0): the hydraulic gradient is simply proportional to the square of the discharge. A diurnal variation of $\mathrm{I}: \sqrt{ } 2$ for the discharge, which is not excessive in summer, would therefore imply a variation of I $: 2$ for the hydraulic head. In the case of the Gornergletscher this means a fluctuation of as much as $200 \mathrm{~m}$, which is too much to allow us to neglect the difference in closure rate between day and night. Equally, the different melt rate in the channel between day and night, which is directly related to the discharge, is not negligible. Without proper analysis of the time dependence it is not possible to say what the exact meaning of the computed mean pressure is, except that the true pressure should fluctuate about this value. The amplitude of the fluctuations, and how close the computed mean pressure is to the maximum or minimum, are open questions. Incidentally, it seems that no pronounced daily fluctuation of pressure has been observed at the Grande Dixence syphon. It is clear that the problem becomes very much more complicated when irregular day-to-day variations as well as variations over longer periods are taken into account. While the analysis of the mean pressure shows that pressure will eventually settle at a low value at high run-off, it is clear that initially, when the discharge begins to increase, the pressure will rise even above the previous high level of low discharge, simply because an excess of water is pouring into a conduit system of low capacity. It is conceivable that this situation prevails over a relatively long period in spring and early summer while the discharge keeps increasing. The drainage system would not fully expand until later in summer, when the drop of pressure below the winter level is to be expected. As the discharge decreases through late summer and autumn the pressure must be expected to fall further, because again the drainage system needs time to adjust. The mean pressure through the season is now different from what the computation has given, with the pressure maximum delayed from winter till late spring, and the minimum from summer till autumn. The notion of the phase shift between discharge and subglacial water pressure has been used by some authors to explain the seasonal variation of glacier motion, i.e. the occurrence of the maximum velocity in late spring and the minimum in late autumn (Elliston, unpublished; Röthlisberger and Aellen, unpublished; Haefeli, 1970; Stenborg, 1970). Müller and Iken (in press) have further shown that the discharge variations over shorter periods have a pronounced effect on the glacier flow, giving an additional indication of how important the time dependence of the discharge must be in relation to the subglacial water pressure.

\section{Glacier Flow}

The only motion of the ice which has been considered in the theory has been the closure of the conduit. Otherwise the ice mass was assumed to be at rest. This is a condition deviating considerably from nature, especially in deep valley glaciers, which have mainly been envisaged in this paper. The bed-slip usually occurring at the base of such glaciers must be of particular concern, since water conduits also located at the bed have mainly been treated. It is obvious that the channels will be directly affected by a sliding motion of the ice. Since the ice pressure is no longer uniformly distributed over the bed, there ought to be preferential paths of reduced ice pressure which the water will follow. In the extreme case the ice can even separate from the bed to form extended water-filled cavities of the type on which Lliboutry ( 1968 ) has based his theory of glacier sliding. They will be located in the pressure shadows down-stream from hummocks. The energy loss of the stream of water in the cavities is negligible, but some of the conduit sections serving as links between 
individual cavities may have to pass through zones of increased ice pressure and thereby show relatively large hydraulic gradients. Consequently the hydraulic grade line of the system of cavities linked by conduits may not differ too much from the uniform conduit assumed in the theoretical model. The transit time of water, however, would be considerably increased. As observed transit times indeed appear to be longer than the theoretical ones, * this may be taken to indicate that cavities exist.

On the basis of the present theory alone one would envisage not only large individual channels, but also a fine network of dendritic veins and intermediate size passages draining the water which originates at the bottom of the glacier from melting by geothermal heat and friction. (Appropriate equations for laminar flow would have to be used in the computations.) However, Weertman (unpublished) has shown that glacier flow will prevent the water from flowing freely into, and maintaining, such a channel system.

\section{WATER ACTION AT THE BED}

The only action of the water considered so far is the melting of ice by frictional heat, but if channels are located at the base of the ice, there will also be some effects on the bed, like erosion. There are many examples where subglacial melt streams have cut deeply into bedrock. Once erosion has started the closure will be reduced and the water pressure will be less than before. An erosion channel is therefore a favoured position for the conduit, but it may not always be easy for the water to start such a channel, considering that the conduit may continuously change its position with the moving glacier, and that the glacier bed also changes due to glacial erosion. Furthermore a subglacial gorge may not only be a favoured place for the water, but also for sediments.

Sedimentation is another possibility for water action at the bed. It is particularly probable that a conduit can become blocked by sediments in a section of an overdeepened glacier bed, where the conduit forms an inverted syphon. This may easily happen at the end of summer when the discharge is reduced and the flow velocity is small due to large conduit diameters. This process again has a direct bearing on the periodical formation of glacial lakes.

\section{A plausible subglacial GHANNEL SYSTEM AND OUTLOOK}

A theory has been developed above for computing water pressure for a certain model of an intra- or subglacial conduit, but it has also been shown that natural subglacial water courses may differ considerably from the assumptions made in the model. It remains now to summarize what the system of subglacial channels might actually look like in nature.

A single large opening of a cross-section close to semi-circular can often be observed at the portal of valley glaciers, and a similar though rather parabolic cross-section has been seen at the outlet tunnel of the Gornersee (Fig. I I). A channel of this general type, parabolic or semi-circular, may well extend in a more or less straight fashion over considerable distances under the glacier, but not necessarily over the full length. On the contrary, gorges may be cut through rock bars, and the conduit may meander or become braided where the hydraulic gradient is small. When the water moves at relatively high pressure through zones of large bed-slip, there may be series of subglacial cavities of Lliboutry type, "pools" in analogy to surface water. Furthermore, it has been seen that the water pressure can under certain conditions reach the equilibrium pressure of the ice. The glacier is then afloat if the hydraulic gradient is zero- a subglacial lake may form under these circumstances. But when the gradient is not zero, the water will have to move either in a pressure pipe entirely surrounded by ice, or, more likely, Weertman-type sheet flow will occur with its consequences

* Note added in proof: Not in general, see the footnote on p. 196 . 
on friction at the bed. With time-dependent discharge it is even conceivable that some sort of "flooding" may sometimes take place, increasing further the area with sheet flow.

In large valley glaciers it is likely that a major channel, the bottom conduit, runs along the thalweg, but two additional main streams may exist at a lesser depth closer to both glacier margins. They are referred to as gradient, or lateral conduits. Only these two lateral streams seem to exist in small, relatively broad flat glacier basins (Stenborg, 1969). With tributaries from the glacier edge and moulins a still more complex system of water courses has to be envisaged, where interconnections may develop along chains of cavities forming behind transverse rock bars. It is in this way, as well as possibly through waterfilled crevasses which extend eventually all the way to the bottom, that the water reaches the bottom channel.

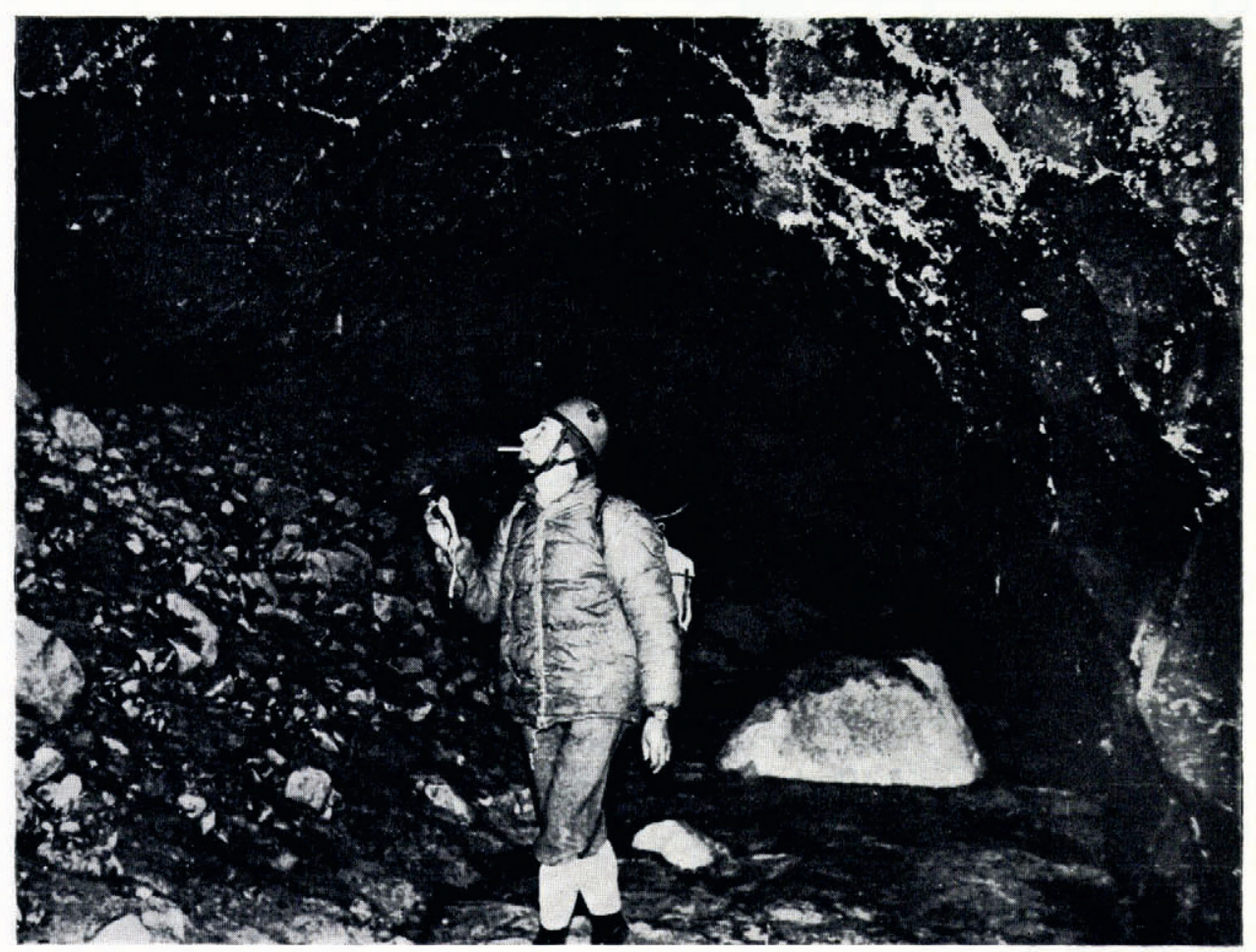

Fig. II. Typical section of the duct leading from a moulin to the similarly shaped main drainage tunnel of Gornersee. (Photograph by Luc Vuadens, Groupe St. Exupéry).

Some insight into the possible behaviour of subglacial water has been achieved by the theoretical analyses of a simple model, and some further success can be anticipated along this line, mainly by trying to take variable discharge with time into account. This is no easy matter, however, and furthermore it is not likely that the theoretical treatment will give all the answers. Direct observations will be needed as well. Transit times should be measured together with water pressure. This too is no easy matter, because the pressure should be known at many different points, involving an extensive drilling programme, and it should be observed not once, but over extended periods of time. Some further efforts to extend our knowledge in the subject seem worthwhile in spite of the great difficulties, considering the practical importance for lake bursts and the close relation to problems of glacier mechanics. 


\section{AcKnowledgements}

The author is primarily indebted to Dipl. Math. Holger Jensen who has contributed substantially to the paper by writing the computer programmes and to Ing. A. Chervet for giving advice on hydraulics theory and translating the summary into French. Thanks are further due to Professor G. Schnitter and his successor Professor D. Vischer as well as Professor $P$. Kasser for their interest in the work, and to various other members of the Versuchsanstalt for their advice and help. The author is grateful to Ing. A. Bezinge of the Grande Dixence power company for furnishing documents on the water pressure measurements at the Gornergletscher, and for his invitation to participate in the visit into the subglacial outlet channel of the Gornersee. By earlier discussions and by letting us have copies of his unpublished manuscripts Dr G. R. Elliston has contributed to the formation of our ideas of subglacial drainage. Professor L. Lliboutry and a referee made valuable comments on the paper, and I am further indebted to Professor J. Weertman for making his unpublished manuscript available to me. Mr David Ward's help in improving the English syntax is also gratefully acknowledged.

MS. received 29 April 197 I and in revised form I2 November 197 I

\section{REFERENCES}

Betts, C. A., and others. 1962. Nomenclature for hydraulics, by C. A. Betts, T. R. Cantine, E. J. Rutter and F. W. Blaisdell. ASCE [American Society of Civil Engineers] Manuals and Reports on Engineering Practice, No. 43.

Bezinge, A., and others. In press. Phénomènes du lac glaciaire du Gorner, par A. Bezinge, J. P. Perreten et F. Schafer. Union Géodésique et Géophysique Internationale. Association Internationale d'Hydrologie Scientifique. Commission des Neiges et Glaces. Symposium on the hydrology of glaciers, Cambridge, 7-13 September 1969, organized by the Glaciological Society.

Butkovich, T. R., and Landauer, J. K. 196o. Creep of ice at low stresses. U.S. Snow, Ice and Permafrost Research Establishment. Research Report 72.

Elliston, G. R. Unpublished. Glaciological studies on the Gornergletscher: II. Water movement through the glacier; III. Changes in surface speed with time. [Written 1966.]

Glen, J. W. 1954. The stability of ice-dammed lakes and other water-filled holes in glaciers. Fournal of Glaciology, Vol. 2, No. 15, p. $316-18$.

Glen, J. W. 1958. The flow law of ice: a discussion of the assumptions made in glacier theory, their experimental foundations and consequences. Union Géodésique et Géophysique Internationale. Association Internationale d'Hydrologie Scientifique. Symposium de Chamonix, $16-24$ sept. 1958, p. $17 \mathrm{I}-83$.

Haefeli, R. 1970. Changes in the behaviour of the Unteraargletscher in the last 125 years. Journal of Glaciology, Vol. 9, No. 56, p. 195-212.

Lang, H. 1966. Hydrometeorologische Ergebnisse aus Abflussmessungen im Bereich des Hintereisferners (Ötztaler Alpen) in den Jahren 1957 bis 1959. Archiv für Meteorologie, Geophysik und Bioklimatologie, Ser. B, Bd. 14, Ht. 3-4, p. 280-302.

Liestøl, O. 1956. Glacier-dammed lakes in Norway. Norsk Geografisk Tidsskrift, Bd. I5, Ht. 3-4, 1955-56, p. $122-49$.

Lliboutry, L. A. I964-65. Traité de glaciologie. Paris, Masson et Cie. 2 vols.

Lliboutry, L. A. 1968. General theory of subglacial cavitation and sliding of temperate glaciers. Fournal of Glaciology, Vol. 7, No. 49, p. $21-5^{8}$.

Mathews, W. H. I964. Water pressure under a glacier. Fournal of Glaciology, Vol. 5, No. 38, p. 235-40.

Mathews, W. H. 1965. Two self-dumping ice-dammed lakes in British Columbia. Geographical Review, Vol. 55, No. I, p. $46-52$.

Mathews, W. H. In press. Record of two jökullhlaups. Union Géodésique et Géophysique Internationale. Association Internationale d'Hydrologie. Scientifique. Commission des Neiges et Glaces. Symposium on the hydrology of glaciers, Cambridge, 7-13 September 1969, organized by the Glaciological Society.

Müller, F., and Iken, A. In press. Velocity fluctuations and water regime at Arctic valley glaciers. Union Géodésique et Géophysique Internationale. Association Internationale d'Hydrologie Scientifique. Commission des Neiges et Glaces. Symposium on the hydrology of glaciers, Cambridge, 7-13 September 1969, organized by the Glaciological Society.

Nye, J. F. I953. The flow law of ice from measurements in glacier tunnels, laboratory experiments and the Jungfraufirn borehole experiment. Proceedings of the Royal Society, Ser. A, Vol. 219, No. I 139, p. 477-89.

Röthlisberger, H., and Aellen, M. Unpublished. Annual and monthly velocity variations on Aletschgletscher. [Paper presented at the general assembly of the International Union of Geodesy and Geophysics, Berne, Switzerland, 1967.$]$

Stenborg, T. I969. Studies of the internal drainage of glaciers. Geografiska Annaler, Vol. 51A, Nos. I-2, p. I3-41.

Stenborg, T. 1970. Delay of run-off from a glacier basin. Geografiska Annaler, Vol. 52A, No. I, p. I-30. 
Vivian, R., and Zumstein, J. In press. Hydrologie sous-glaciaire au glacier d'Argentière (Mont Blanc, France). Union Géodésique et Géophysique Internationale. Association Internationale d'Hydrologie Scientifique. Commission des Neiges et Glaces. Symposium on the hydrology of glaciers, Cambridge, 7-13 September 1969, organized by the Glaciological Society.

Weertman, J. 1964. The theory of glacier sliding. Journal of Glaciology, Vol. 5, No. 39, p. $287-303$.

Weertman, J. I969. Water lubrication mechanism of glacier surges. Canadian fournal of Earth Sciences, Vol. 6 , No. 4 , Pt. 2, p. $929-42$.

Weertman, J. Unpublished. General theory of water flow at the base of a glacier or ice sheet.

Williams, G. P. 1970. Manning formula - a misnomer? Journal of the Hydraulics Division, American Society of Civil Engineers, Vol. 96, No. HY 1, p. 193-200; discussion, Vol. 96, No. HY 9, p. 1910-14. 